IZA DP No. 6304

Testing Canonical Tournament Theory: On the Impact of Risk, Social Preferences and Utility Structure

Roman M. Sheremeta

Steven Y. Wu

January 2012 


\title{
Testing Canonical Tournament Theory: On the Impact of Risk, Social Preferences and Utility Structure
}

\author{
Roman M. Sheremeta \\ Chapman University \\ Steven Y. Wu \\ Purdue University \\ and IZA
}

Discussion Paper No. 6304
January 2012

IZA

P.O. Box 7240

53072 Bonn

Germany

Phone: +49-228-3894-0

Fax: +49-228-3894-180

E-mail: iza@iza.org

\begin{abstract}
Any opinions expressed here are those of the author(s) and not those of IZA. Research published in this series may include views on policy, but the institute itself takes no institutional policy positions.

The Institute for the Study of Labor (IZA) in Bonn is a local and virtual international research center and a place of communication between science, politics and business. IZA is an independent nonprofit organization supported by Deutsche Post Foundation. The center is associated with the University of Bonn and offers a stimulating research environment through its international network, workshops and conferences, data service, project support, research visits and doctoral program. IZA engages in (i) original and internationally competitive research in all fields of labor economics, (ii) development of policy concepts, and (iii) dissemination of research results and concepts to the interested public.
\end{abstract}

IZA Discussion Papers often represent preliminary work and are circulated to encourage discussion. Citation of such a paper should account for its provisional character. A revised version may be available directly from the author. 


\section{ABSTRACT}

\section{Testing Canonical Tournament Theory: On the Impact of Risk, Social Preferences and Utility Structure ${ }^{*}$}

We use experiments to test comparative statics predictions of canonical tournament theory. Both the roles of principal and agent are populated by human subjects, allowing us to test predictions for both incentive responses and optimal tournament design. Consistent with theory, we observed an incentive effect from raising the winner's prize. However, we also observed several empirical puzzles that appeared to contradict theory. Controlling for social preferences did not resolve the puzzles, although social preferences do influence behavior. It turns out that the puzzles can be explained by the canonical model once the textbook assumption of separable agent utility is relaxed.

JEL Classification: D03, D82, D86, M52, M55

Keywords: $\quad$ tournaments, experiment, social preferences, contract theory

Corresponding author:

Steven Y. Wu

Department of Agricultural Economics

Purdue University

403 West State Street

West Lafayette, IN 47906-2056

USA

E-mail: sywu@purdue.edu

\footnotetext{
${ }^{*}$ We thank Dmitry Ryvkin, Andrew Schotter, and seminar participants at Purdue University, University of Arizona, and the North American Economic Science Association Conference in Tucson for helpful comments. Any remaining errors are ours. The authors gratefully acknowledge financial support provided by the USDA-Economic Research Service cooperative agreement number 58-6000-7-0096. We also thank the Economic Science Institute at Chapman University for providing facilities in conducting the experiment.
} 
While both theorists and experimental economists have proposed and tested an array of extensions to the original model of Lazear and Rosen (1981), henceforth LR, we know of no research that comprehensively examines how the barebones canonical theory performs empirically. Therefore, we use economic experiments to test the qualitative predictions of LR's theory. Our goal is to identify where the canonical model is weak and therefore should be modified and where the model is strong so that we can avoid fixing problems that are not broken. We hope that insights from our study will provide a more efficient roadmap for future work on tournaments. Additionally, most prior experimental research on tournaments focus on the agent side of the principal-agent (PA) relationship. Our study extends the literature by testing the comparative statics predictions of both sides of the PA model. We place some subjects into the role of agents so we can observe their responses to tournament structure, but we also place some subjects in the role of the principal to determine whether subjects can design optimal tournaments that are consistent with theory. Given that tournament theory continues to be an active area of research and provides an important theory of incentive design for many applied subfields in both economics and business, we believe that a better understanding of where canonical tournament theory succeeds and fails is of first order importance.

Many economists now recognize that simple models inevitably "fail" in the literal sense and yet can be very useful in generating important insights (Samuelson 2005; Rubinstein 2006). Thus, our focus is not to test the truth value of the model, but rather to focus on the qualitative implications of classical tournament theory. If a theory cannot even generate comparative statics predictions that are qualitatively consistent with the data, then it would be difficult to argue that the theory is useful.

Consistent with theory and prior literature, our experimental results show that increasing the prize spread (difference between the winner's prize and loser's prize) by raising the winner's prize robustly increases agent's effort. However, several qualitative empirical puzzles also emerged. First, when the prize spread is reduced by increasing the loser's prize, this does not appear to reduce agent effort. Textbook theory predicts that effort should decrease whenever the power of incentives is reduced regardless of whether 
that reduction is due to a decrease in the winner's prize or an increase in the loser's prize. Second, if the loser's prize is increased while holding the prize spread constant, agents appear to increase their effort. The loser's prize is analogous to a base wage and standard theory predicts that the base price should play no incentive role. Third, subjects assigned to be principals did not appear to reduce the prize spread when contracting with more risk-averse agents which is another textbook theoretical prediction. Fourth, subjects assigned to be principals choose seemingly generous loser's prizes that leave nearly all rents to agents. Standard theory predicts that when the principal is making take-it-orleave-it offers, the principal should grab most of the surplus.

The above puzzles ostensibly contradict classical theory and might appear to be consistent with a model of social preferences such as inequality aversion or gift-exchange (Akerlof 1982; Fehr, Kirchsteiger, and Riedl 1993; Fehr and Schmidt 1999; Bolton and Ockenfels 2000). Social preferences are naturally appealing for studying tournaments since tournaments structurally impose inequality in payoffs across agents (Grund and Sliwka 2005). However, we elicited subjects' social preferences prior to the tournaments, which allowed us to control for social preferences. We also conducted treatments that allowed us to isolate attribution based social preferences (Charness 2004). We found that our puzzles remained even after controlling for social preferences.

It turns out that we can explain the puzzles by altering a simple assumption that is widely adopted in the contracting literature: the additive separability of the agent's utility function in income and effort. The general risk literature defines Bernoulli utility over wealth which should, in principle, also include effort costs if costs are given in monetary units. However, the standard approach in the principal-agent literature is to treat effort cost as "disutility" rather than wealth. Instead, wealth typically refers to transfers that are made from the principal to the agent. ${ }^{1}$ Ironically, the original LR model did not assume separability, but subsequent studies that focus on risk aversion adopted this assumption to simplify modeling. For example, Green and Stokey (1983) incorporate this assumption but caution that qualitative results might change because it eliminates income effects.

\footnotetext{
${ }^{1}$ Laffont and Martimort (2002) discuss this issue in detail in Section 5.3 of their textbook.
} 
The separability assumption is now the standard assumption in the contract theory literature and most textbook treatments of tournaments impose this assumption. We generated a new set of comparative static predictions under the assumptions of risk aversion and non-separable agent utility and found the comparative statics predictions to be qualitatively consistent with nearly all of the empirical regularities in our experiment. Moreover, the non-separable model yields an even richer set of predictions, which could not be rejected by the data. Thus, the separability assumption is not innocuous and can mean the difference between rejecting the theory or harnessing the power of the theory.

The main implication of our findings is that canonical tournament theory with selfish agents performs remarkably well once we relax a restrictive assumption. But more broadly, our research shows how the explanatory power of standard models based on strictly self-interested subjects are often held back by our failure to carefully scrutinize assumptions about functional forms on important economic primitives. Such scrutiny might be warranted prior to rejecting theory based on selfish preferences and proposing alternative behavioral models based on social preferences and perhaps other behavioral motives. In our case, relaxing the separability assumption has a profound effect on agents' marginal cost of effort which can alter even qualitative predictions and uncover new insights about the incentive instruments available to principals. Our finding supports a point made by Levine and Zheng (forthcoming) that "many important paradoxes arise because theory is incorrectly applied" and that sometimes the simplest theory based on selfish preferences can perform quite well.

Having said the above, we also want to emphasize that, while controlling for social preferences did not appear to resolve the empirical puzzles, our social preference variables had significant direct effects on outcomes. Thus social preferences should not be dismissed. The impact of social preference variables on both agent effort and principal's choice of prizes was both statistical significant and consistent with intuition. Moreover, our attribution treatment showed that social preferences can be turned on and off depending on whether subjects viewed decisions of counterparties as being assigned mechanically (by a computer) or by another human being. In short, while we suggest that 
one should not immediately replace standard models with social preference models when experimental data deviates from theoretical predictions, social preferences do have significant explanatory power and therefore should be used to build richer models. Our results suggest that social preferences and standard models should be seen as modeling complements rather than substitutes for future work on tournaments.

\section{Related Literature}

Tournament theory is well established and has reached textbooks (e.g., Bolton and Dewatripont 2005). Given the vast literature on tournaments, we only review literature that is directly relevant to our research. To motivate our contribution, we begin by pointing out that most prior experimental literature on tournaments focus on "incentive effects," which is to examine how agents respond to tournament prize structures (for a review see, Charness and Kuhn 2011). Typically, the tournament scheme is exogenously imposed on agents by experimenters and there is no explicit interaction within the experiment between agents and principals. In some cases, new institutional constraints are added and/or behavioral extensions have been proposed to buttress the basic tournament model. These studies have been very insightful and have increased our knowledge about the agent side of tournaments models. Examples of these studies include, but are not limited to Bull, Schotter, and Weigelt (1987), Schotter and Weigelt (1992), Nalbantian and Schotter (1997), Orrison, Schotter, and Weigelt (2004), Wu and Roe (2005), Harbring and Irlenbusch (2005), Eriksson, Teyssier, and Villeval (2009), Cason, Masters, and Sheremeta (2010), Freeman and Gelber (2010) and Nieken (2010). Our study extends this previous literature by adding the principals to the PA relationship. The importance of this extension derives from the fact that the canonical theory emphasizes both incentive response and incentive design. Thus, allowing subjects to endogenously design tournament prizes permits a more comprehensive examination of the theory. ${ }^{2}$ While we are not the first to allow subjects to endogenously choose

\footnotetext{
${ }^{2}$ Perhaps one reason researchers have focused on the agent side is because there is a concern that it is easier for "normal people" such as college undergrads to respond to incentives rather than design incentives. In practice, principals tend to be employers or companies who are "sophisticated' relative to the general
} 
tournament prizes, we are not aware of any experimental study that allows subjects to design optimal tournaments consistent with the LR model. This is a unique feature of our study. Falk, Fehr, and Huffman (2008) and Harbring and Irlenbusch (2005) both conduct novel and insightful studies in which subjects select tournament contracts to offer to other subjects who play the role of agents. However, their fundamental goals are different than ours. Whereas their studies focus on the impact of sabotage and/or loss aversion on tournament incentives, our goal is to test qualitative predictions of a stripped down canonical tournament model. We simply want to test the classic LR model "as is" without introducing sabotage or behavioral assumptions. However, if we are to properly study the LR theory, we must assume as a starting point that the principal designs an optimal contract. In the optimal contract, not only does the principal have to choose the correct prize spread, but the principal also has to ensure agent participation. Thus, the principal optimizes over tournament prizes subject to both incentive compatibility and participation constraints. ${ }^{3}$ An optimal contract must be disciplined by both constraints because there is a tradeoff between stronger incentives and participation. ${ }^{4}$

Accordingly, in designing our experiment, we are guided by the "complete contracts" methodology (e.g., Tirole 1999) in that we impose very few restrictions on the principal's contract choice set. ${ }^{5}$ It is well known that optimal incentives depend on agents' risk preferences, which are largely unobservable to the experimenter ex ante. Thus, we were careful not to impose specific contractual forms on subjects. We allow subjects to choose both the winner's and loser's prizes freely. This reduces the odds that optimal tournament contracts are not inadvertently excluded by our design.

population. Thus, it is possible that using students as subjects might stack the odds against the theory. However, if subjects are able to behave in a way that is consistent with optimal tournament design despite the stacked odds, then we would have very compelling support for the theory.

${ }^{3}$ In the original LR model, it is assumed that competition for labor dissipates principals' rents. We modify this assumption and adopt the modern approach of assuming that the principal makes take-it-or-leave-it offers to the agent. Thus, the zero profit condition for the principal will be replaced with a participation constraint for the agent.

${ }^{4}$ Without the discipline of a participation constraint, the principal should theoretically offer the strongest possible incentives to the agent.

${ }^{5}$ For instance, many experimenters impose specific contractual forms on subjects. However, the imposed contractual forms are likely to be suboptimal since experimenters rarely know agents' risk preferences. 


\section{The Standard Tournament Model}

We begin by outlining a canonical tournament model and use it to derive comparative statics predictions and to motivate our experimental design. Most of the theory outlined here is not new and many of the insights can be found scattered across various papers in the literature. However, a self-contained analysis is useful to help organize thoughts and highlight key testable predictions.

Consider a two player tournament in which a risk-neutral principal hires two riskneutral agents to perform a task. Let $y_{i}$ denote agent $i$ 's performance which is stochastically related to effort $e_{i}$ via the function $y_{i}=e_{i}+\varepsilon_{i}$, where $\varepsilon_{i}$ is a random variable with mean zero and density function $f\left(\varepsilon_{i}\right)$. Assume that the $\varepsilon_{i}$ 's are i.i.d. across agents with mean zero. Agents exert effort prior to knowing the realization of $\varepsilon_{i}$. Effort cost is given by $c\left(e_{i}\right)$, where $c^{\prime}\left(e_{i}\right)>0$ and $c^{\prime \prime}\left(e_{i}\right)>0$. The principal can observe only the performance $y_{i}$ by each agent, and not effort $e_{i}$ so the potential for moral hazard exists.

In a two player tournament, the principle offers two prizes $W_{1}$ and $W_{2}$, where $W_{1}$ $>W_{2}$. The higher performing agent receives $W_{1}$ and the other agent receives $W_{2}$. The probability of agent $i$ outperforming agent $j$ is given by $p_{i}=\operatorname{Pr}\left(y_{i}>y_{j}\right)=\operatorname{Pr}\left(e_{i}+\varepsilon_{i}>e_{j}+\right.$ $\left.\varepsilon_{j}\right)=\int F\left(e_{i}-e_{j}+\varepsilon\right) f(\varepsilon) d \varepsilon$. Assume that $\frac{\partial p_{i}}{\partial e_{i}}=p_{i e}>0$. Agents must make their effort decisions simultaneously and the expected profit for a risk-neutral agent is:

$$
E\left(\pi_{i}^{A}\right)=p_{i} W_{1}+\left(1-p_{i}\right) W_{2}-c\left(e_{i}\right)=W_{2}+p\left(W_{1}-W_{2}\right)-c\left(e_{i}\right) .
$$

Note that agents compete with each other by playing a simultaneous move game $G\left[e_{i}, e_{j} ; E\left(\pi_{i}^{A}\right), E\left(\pi_{j}^{A}\right)\right]$. The best response for each agent is ${ }^{6}$

$$
\frac{\partial E\left(\pi_{i}^{A}\right)}{\partial e_{i}}=\frac{\partial p_{i}}{\partial e_{i}}\left(W_{1}-W_{2}\right)=\frac{d c\left(e_{i}\right)}{d e_{i}} .
$$

Since the two agents are identical, it follows that, for $i \neq j$

\footnotetext{
${ }^{6}$ Equation (2) can be written more explicitly as $\left(W_{1}-W_{2}\right) \int f^{2}(\varepsilon) d \varepsilon=c^{\prime}\left(e_{i}\right)$. However, we maintain the simpler form given in (2) to facilitate ease of interpretation and to be consistent with prior literature on tournaments.
} 


$$
\frac{d c\left(e_{j}\right)}{d e_{j}}=\frac{\partial p_{i}}{\partial e_{i}}\left(W_{1}-W_{2}\right)=\frac{d c\left(e_{i}\right)}{d e_{i}} .
$$

Assuming that $\frac{\partial p_{i}}{\partial e_{i}}\left(W_{1}-W_{2}\right)>\frac{d c(0)}{d e_{i}}$, LR suggest that if the objective function is sufficiently concave, then (3) implies that there is a symmetric Nash equilibrium such that $e_{i}=e_{j}=e^{*}\left(W_{1}, W_{2}\right)$. With identical effort, there is a $50 \%$ chance that each agent will win the tournament.

\section{A. Analysis of Incentives}

The reaction function (2) can be used to conduct comparative statics analysis of how an agent will respond to changes in the tournament prize structure.

Proposition 1: A risk-neutral agent optimally responds to a change in tournament prize structure as follows:

a) Effort increases with an increase in $W_{1}$ holding $W_{2}$ constant (prize spread increases);

b) Effort decreases in $W_{2}$ holding $W_{1}$ constant (prize spread decreases);

c) Effort does not change with a change in $W_{2}$ holding prize spread constant;

d) An increase in either the prize spread or $W_{2}$ (holding the other constant) relaxes agents' participation constraint and induces more participation.

Proof: Proofs to all propositions and corollaries are in Appendix A.

Proposition 1 assumes risk neutrality, but the next Proposition 2 shows that all of the qualitative predictions of Proposition 1, with the exception of (c), still hold when agents are risk-averse and have utility that is additively separable in income and effort. The separability assumption, however, may only be appropriate if effort cost is measured in disutility units. If effort cost is measured in monetary units, then the Bernoulli utility function would have to be defined over wealth which is $W-c(e)$. This would make the separability assumption inappropriate. The correct specification of the utility function is ultimately an empirical question which we address in this study. ${ }^{7}$ Nonetheless, the

\footnotetext{
${ }^{7}$ Most experimental studies of tournaments employ the assumption of risk neutrality, i.e. Bull, Schotter, and Weigelt (1987), Schotter and Weigelt (1992), Nalbantian and Schotter (1997), Orrison, Schotter, and Weigelt (2004), Harbring and Irlenbusch (2005), Eriksson, Teyssier, and Villeval (2009) and Nieken
} 
contract theory literature typically treats effort cost as disutility, so separability has become the standard assumption. Principal-agent models with separable agent utility yield a number of predictions that are commonly associated with "rational" incentive responses by self-interested agents. This is also true of tournament models.

Proposition 2: Suppose that an agent's expected utility is such that $E\left[U\left(\pi_{i}^{A}\right)\right]=p_{i} u\left(W_{1}\right)+\left(1-p_{i}\right) u\left(W_{2}\right)-c\left(e_{i}\right)$ where $u^{\prime}(\bullet)>0$ and $u^{\prime \prime}(\bullet)<0 .{ }^{8}$ Then:

a) Effort increases with an increase in $W_{1}$ holding $W_{2}$ constant;

b) Effort decreases in $W_{2}$ holding $W_{1}$ constant;

c) Effort is decreasing in $W_{2}$ holding prize spread $\left(W_{1}-W_{2}\right)$ constant;

d) An increase in either the prize spread or $W_{2}$ (holding the other constant) relaxes agents' participation constraint and induces more participation.

Propositions 1(c) and 2(c) differ because under 1(c) incentives come from the prize spread. If the prize spread is held constant, changes in $W_{2}$ will not affect effort. However, with risk aversion, incentives do not come from the prize spread but from $u\left(W_{1}\right)-u\left(W_{2}\right)$. Even if the prize spread is held constant, raising $W_{2}$ will decrease the utility spread given concavity of the utility function. Taken together, Propositions 1 and 2 provide a set of testable hypotheses about how agents will respond to prize structure.

\section{B. Optimal Prize Structures}

To design an optimal tournament, a forward looking principal anticipates agents' equilibrium effort responses and chooses prizes that maximize her expected profit. With two agents and a symmetric equilibrium, the principal's optimal contract design problem

(2010). On the other hand, to the best of our knowledge, the only two experimental studies of rank-order tournaments that relax the assumption of risk neutrality are done by Wu and Roe (2005), who employ a non-separable utility function, and Agranov and Tergiman (2011), who employ a separable utility function. ${ }^{8}$ One might question our assumption that utility is identical across agents because, in practice, risk preferences might be heterogeneous due to differences in initial wealth and risk tolerances. Nonetheless, the most useful theories are often those that provide simple abstractions from reality while producing robust comparative statics predictions. Thus, if our simple model with identical agents can generate comparative statics predictions that are consistent with the data, we consider this a virtue. While adding additional assumptions might improve predictive power in very specific environments, there is a potential cost in that predictive power might be reduced across different environments thereby reducing generalizability. 
is to maximize expected profit subjective to the agents' participation and incentive compatibility constraints. That is, the principal solves,

(4) $\max _{W_{1}, W_{2}} 2\left[e^{*}\left(W_{1}, W_{2}\right)-\frac{1}{2}\left(W_{1}+W_{2}\right)\right]$

s.t. $E\left(\pi_{i}^{A}\right)=p_{i} W_{1}+\left(1-p_{i}\right) W_{2}-c\left[e^{*}\left(W_{1}, W_{2}\right)\right] \geq v$

where $e^{*}\left(W_{1}, W_{2}\right)$ represents the symmetric Nash equilibrium effort profile determined by (3), thereby ensuring incentive compatibility.

Proposition 3: The solution to (4) yields and optimal tournament structure:

a) $\quad W_{2}^{*}=v+c\left[e^{*}\left(W_{1}^{*}, W_{2}^{*}\right)\right]-\frac{c^{\prime}\left[e^{*}\left(W_{1}^{*}, W_{2}^{*}\right)\right]}{2 p_{e}}$;

b) $\quad W_{1}^{*}=v+c\left[e^{*}\left(W_{1}^{*}, W_{2}^{*}\right)\right]+\frac{c^{\prime}\left[e^{*}\left(W_{1}^{*}, W_{2}^{*}\right)\right]}{2 p_{e}}$;

c) $1=c^{\prime}\left[e^{*}\left(W_{1}^{*}, W_{2}^{*}\right)\right]$.

This contract is optimal under the assumption of agent risk neutrality, which may or may not hold in reality. But it allows us to parameterize our model to generate risk neutral point predictions which can serve as a natural benchmark. We also derive the optimal tournament under agent risk aversion. ${ }^{9}$

Proposition 4: The optimal tournament when agents have expected utility such that $E\left[u\left(\pi_{i}^{A}\right)\right]=p_{i} u\left(W_{1}\right)+\left(1-p_{i}\right) u\left(W_{2}\right)-c\left(e_{i}\right)$, where $u^{\prime}(\bullet)>0$ and $u^{\prime \prime}(\bullet)<0$, is:

a)

b)

$$
\begin{aligned}
& W_{2}^{*}=u^{-1}\left[v+c\left[e^{*}\left(W_{1}^{*}, W_{2}^{*}\right)\right]-\frac{c^{\prime}\left[e^{*}\left(W_{1}^{*}, W_{2}^{*}\right)\right]}{2 p_{e}}\right] ; \\
& W_{1}^{*}=u^{-1}\left[v+c\left[e^{*}\left(W_{1}^{*}, W_{2}^{*}\right)\right]+\frac{c^{\prime}\left[e^{*}\left(W_{1}^{*}, W_{2}^{*}\right)\right]}{2 p_{e}}\right] ;
\end{aligned}
$$

c)

$$
e^{*}\left(W_{1}^{*}, W_{2}^{*}\right) \in \underset{e}{\arg \max } 2\left\{e-\frac{1}{2}\left(u^{-1}\left[v+c[e]+\frac{c^{\prime}[e]}{2 p_{e}}\right]+u^{-1}\left[v+c[e]-\frac{c^{\prime}[e]}{2 p_{e}}\right]\right)\right\} \text {. }
$$

Part (c) states that the optimal effort level maximizes the principal's expected profit. The term $u^{-1}\left[v+c[e]+\frac{c^{\prime}[e]}{2 p_{e}}\right]+u^{-1}\left[v+c[e]-\frac{c^{\prime}[e]}{2 p_{e}}\right]$ in (c) is the principal's

\footnotetext{
${ }^{9}$ The details of the derivation are in the Appendix A.
} 
incentive cost function from contracting with risk-averse agents. This incentive cost function is the sum of convex transformations of the terms $v+c[e]+\frac{c^{\prime}[e]}{2 p_{e}}$ and $v+c[e]-\frac{c^{\prime}[e]}{2 p_{e}}$. In the absence of risk aversion, the sum of these latter terms is the incentive cost function. But with risk aversion, the incentive cost function is more convex making it more costly to implement high effort. ${ }^{10}$ Thus, the main comparative static implication of increasing agent's risk aversion is that the principal will implement lower effort, which manifests as a reduction in the strength of incentives (prize spread).

\section{Experimental Design and Procedures}

To implement our experiment, we have to impose functional forms and parameters on the model of Section 2. We assume that $c\left(e_{i}\right)=\frac{e_{i}^{2}}{c}$ and $p_{i}=\frac{1}{2}+\frac{e_{i}-e_{j}}{2 a}-\frac{\left(e_{i}-e_{j}\right)^{2}}{8 a^{2}}$. The latter is derived under the assumption that $\varepsilon_{i}$ is uniformly distributed on $[-a, a]$. We also impose the parameter values $a=40, c=120$, and $v=15$. Based on these restrictions, our model predicts that, if agents are risk-neutral, the principal should offer a contract $\left(W_{1}{ }^{*}=85, W_{2}{ }^{*}=5\right)$ and earn $E\left(\pi^{p}\right)=30$. Each agent should exert effort of $e^{*}=60$ and earn expected payoff of $E\left(\pi_{i}^{A}\right)=15$. Under these parameterizations, the second order condition for the agent's objective function is always satisfied ensuring global concavity.

Each experimental session proceeded in three parts. At the beginning of each part, subjects were given instructions, which are available in Appendix B, and the experimenter read the instructions aloud. Subjects also completed a quiz on the computer to verify their understanding. In the first part, we elicited subjects' risk preferences, using 15 binary lottery choices, similar to Holt and Laury (2002). In the second part, we elicited subjects' social preferences using 4 simple binary choices that affected the

\footnotetext{
${ }^{10}$ This is a well-known textbook result in the general principal-agent literature. For example, Laffont and Martimort (2002) provide a detailed discussion throughout the sections on moral hazard. We show that this insight continues to hold for tournaments.
} 
participant's income and the income of another anonymously matched subject, similar to Bartling et al. (2009). These elicitation methods are discussed in detail later in the paper.

In the third part of the experiment, subjects were assigned to one of two tournament treatments, Exogenous and Endogenous. In the Endogenous treatment, some subjects were randomly assigned to be principals who designed tournaments $\left(W_{1}, W_{2}\right)$. In the Exogenous treatment, the computer exogenously assigned $\left(W_{1}, W_{2}\right)$ using the tournaments from a previous Endogenous treatment. Assigning $\left(W_{1}, W_{2}\right)$ from previous Endogenous sessions ensures that the overall distribution of $\left(W_{1}, W_{2}\right)$ is identical across Endogenous and Exogenous. Thus, we can test whether effort and participation are affected by whether the tournaments were chosen by other subjects or exogenously determined by a computer. Having endogenous versus exogenous assignment is similar to the design used by Charness (2004) within the context of a gift-exchange game. This comparison can isolate the impact of attribution based social preferences.

In each tournament session, there were 20 periods of play. At the start of each period in the Endogenous treatment, 18 subjects were randomly placed into six three player groups. In each group, two subjects were assigned as agents and one subject was assigned as a principal. Subjects stayed in the same role for the entire experiment. In the Exogenous treatment, 12 subjects were randomly placed into six two-agent groups. Once a period ended, subjects were randomly and anonymously re-grouped. For the Endogenous treatment, each period had two stages. In the first stage, the principal chose values for $W_{1}$ and $W_{2}$ between 0 and $110{ }^{11}$ In the second stage, the two agents individually decided whether to accept the tournament offer. The Exogenous treatment only had the second stage. The tournament was implemented only if both agents accepted. If rejected, the period ended and agents received reservation payoffs of 15 , while the principal received 0 . If both agents accepted, then agents had to individually

\footnotetext{
${ }^{11}$ The upper bound of 110 was chosen to guarantee the existence of pure strategy Nash equilibrium under risk neutrality. Tournaments with no pure strategy Nash equilibria are more complicated and only partial theoretical characterization of equilibria exists Che and Gale (2000). Thus, the restriction between 0 and 110 is imposed in to guarantee the existence of pure strategy Nash equilibrium for any prize value chosen by the principal. The restriction is not binding theoretically since under risk neutrality the optimal prize values are 85 and 5 .
} 
choose an integer effort level between 0 and 120. Subjects had a table which showed the quadratic cost associated with each effort level. After both agents chose their effort, the computer added a "personal random number" corresponding to the production noise to determine performance. The computer then compared the performance of the two agents and the higher performing agent received $W_{1}$, while the other agent received $W_{2}$. Then all outcomes for the period are displayed on the screen and the experiment proceeded to the next period. Note that $W_{1}$ and $W_{2}$ can vary each period depending on what student principals did. This potentially makes it more difficult for subjects to learn and converge for a fixed set of parameters. The tradeoff is that it creates more variation in responses to facilitate regression analysis and testing of our comparative statics predictions. We felt that this tradeoff is appropriate because a demanding learning environment is a more challenging test for the theory. Thus, if empirical patterns are still consistent with predictions, then this offers more compelling support for the theory.

A total of 120 subjects participated in eight sessions. The four Endogenous sessions had 18 subjects (6 groups) each and the four Exogenous sessions had 12 subjects (6 groups) each. Subjects were undergraduate students who participated in only one session though some had participated in other unrelated economics experiments. The experiment was computerized using z-Tree (Fischbacher 2007). All choices and information were transmitted via computer terminals. At the end of each experiment, 4 out of 20 periods were randomly selected for payment. The sum of the earnings for these 4 periods was exchanged at rate of 20 francs $=\$ 1$. Subjects were also paid for 1 out of 15 and 1 out of 4 decisions made in parts one and two of the experiment. All subjects received a participation fee of $\$ 20$ to cover potential losses. On average, subjects earned \$28 each (maximum \$42 and minimum \$7), which was paid anonymously and in cash. The experimental sessions lasted for about 90 minutes.

\section{Results}

\section{A. Descriptive Statistics}

Table 1 reports equilibrium predictions along with summary statistics of actual results. 
Table 1: Equilibrium Predictions and Experimental Results

\begin{tabular}{|c|c|c|c|c|c|}
\hline Treatments & Equilibrium & \multicolumn{2}{|c|}{ Endogenous } & \multicolumn{2}{|c|}{ Exogenous } \\
\hline Noise Parameter, $a$ & 40 & \multicolumn{2}{|c|}{40} & \multicolumn{2}{|c|}{40} \\
\hline Cost Parameter, $c$ & 120 & \multicolumn{2}{|c|}{120} & \multicolumn{2}{|c|}{120} \\
\hline Outside Option, $v$ & 15 & \multicolumn{2}{|c|}{15} & \multicolumn{2}{|c|}{15} \\
\hline & & $\begin{array}{c}\text { Actual } \\
\text { Offered } \\
\text { (Median) }\end{array}$ & $\begin{array}{c}\text { Actual } \\
\text { Executed } \\
\text { (Median) }\end{array}$ & $\begin{array}{c}\text { Actual } \\
\text { Offered } \\
\text { (Median) }\end{array}$ & $\begin{array}{c}\text { Actual } \\
\text { Executed } \\
\text { (Median) }\end{array}$ \\
\hline First Prize, $W_{1}$ & 85 & 70 & 75 & -- & -- \\
\hline Second Prize, $W_{2}$ & 5 & 20 & 20 & -- & -- \\
\hline Probability of Entry & 1.00 & -- & 0.73 & -- & 0.84 \\
\hline Effort, $e$ & 60 & -- & 42 & -- & 38.5 \\
\hline Principal's Profit & 30 & $-12.5^{\mathrm{a}}$ & $-13.1^{b}$ & $-12.5^{\mathrm{a}}$ & $-8.1^{\mathrm{b}}$ \\
\hline Agent's Profit & 15 & $32^{\mathrm{a}}$ & $28.6^{\mathrm{b}}$ & $32^{\mathrm{a}}$ & $28.1^{\mathrm{b}}$ \\
\hline
\end{tabular}

${ }^{a}$ Indicates the ex ante profit under the tournament offered if agents exert incentive compatible effort levels.

${ }^{b}$ Indicates the actual realized profit under the tournaments. This excludes realized profits from rejected contracts where subjects earned reservation payoffs.

Several observations emerge. First, the median offer of 70 for $W_{1}$ in the Endogenous treatment is lower than the predicted level of 85 . This offer increases to 75 when we focus only on offers that resulted in tournaments being executed (both agents accept the contract). Second, the median offer of 20 for $W_{2}$ is much higher than the predicted level of 5. Thus, the median prize spread $W_{1}-W_{2}$ is 50 (or 55 for executed tournaments), which is less than the predicted level of 80 . Third, median effort is lower than the predicted level of 60 in both treatments, which is consistent with the low prize spread. Fourth, the probability that an agent accepts an offer is 0.73 in the Endogenous treatment and 0.84 in the Exogenous treatment. Even if principals offer contracts that satisfy the participation constraint for risk-neutral agents, risk-averse agents may still reject such contracts so observing some rejections is not unexpected. Fifth, the distribution of profits is extremely unbalanced in favor of agents. "Offered" profit is calculated under the assumption that the risk-neutral agent exerts the incentive compatible effort level under the offered tournament. The median level of both offered and realized profit is negative for the principal. This is unexpected given that the principal is the one that makes the take-it-or-leave it offers. This is a puzzle that will be discussed later.

We also present time series to show the evolution of outcomes over the length of the experiment. Figure 1 plots the evolution of tournament prizes $W_{1}$ and $W_{2}$. 


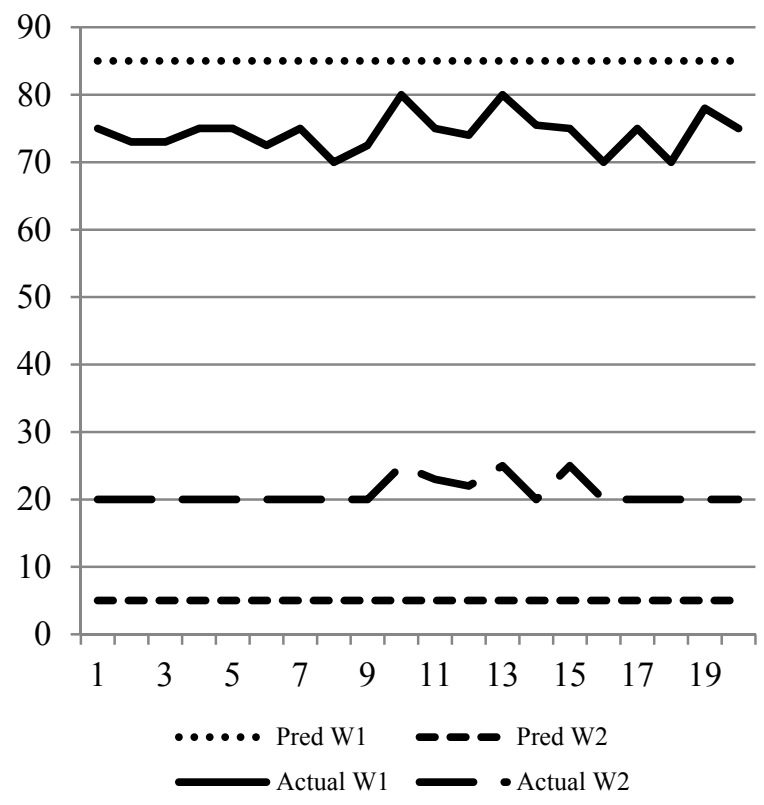

Figure 1: Median Predicted and Actual Prizes by Periods

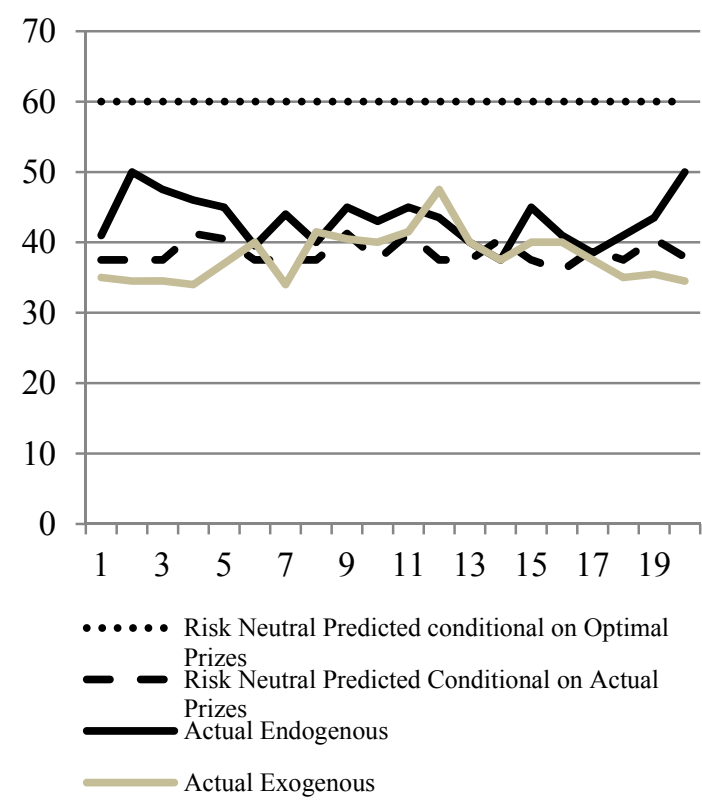

Figure 2: Actual and Predicted Median Effort by Periods

There appears to be no trending toward the predicted levels over time. Figure 2 plots effort across periods. Again, we see little evidence of a time trend or convergence toward the predicted effort level of 60 under the optimal risk-neutral contract. However, actual effort is fairly close to the predicted effort under the contracts that were actually offered. This is fairly consistent with the findings of Bull, Schotter, and Weigelt (1987) in that the average effort tends to converge to the predicted effort given the prize spread.

\section{B. Testing for Incentive Effects}

Propositions 1 and 2 make the following predictions about how agents respond to prizes: (a) an increase in $W_{1}$, holding $W_{2}$ constant, should increase effort; (b) an increase in $W_{2}$ while holding $W_{1}$ constant should lower effort; (c) effort is non-increasing in $W_{2}$, holding prize spread constant (Propositions 1 and 2 combined); and (d) an increase in either the prize spread or $W_{2}$ (holding the other constant) relaxes agents' participation constraint. To test predictions (a) and (b), we ran censored regressions for effort (bounded between 0 and 120) and report results in Table 2 on the next page. The right hand side variables are listed in the left- hand column. The last two regressions include the elicited social 
preference variables. All regressions include period and period-squared time trends, and were estimated with robust standard errors that are adjusted for clustering on sessions.

Table 2: Censored Regression for Effort

\begin{tabular}{|c|c|c|c|c|c|}
\hline & $(1)$ & $(2)$ & (3) & $(4)$ & $(5)$ \\
\hline & $\begin{array}{c}\text { All } \\
\text { Data }\end{array}$ & $\begin{array}{c}\text { Endogenous } \\
\text { Data }\end{array}$ & $\begin{array}{c}\text { Exogenous } \\
\text { Data }\end{array}$ & $\begin{array}{c}\text { Endogenous } \\
\text { Data }\end{array}$ & $\begin{array}{c}\text { Exogenous } \\
\text { Data }\end{array}$ \\
\hline Constant & $\begin{array}{c}1.65 \\
(5.49)\end{array}$ & $\begin{array}{c}10.1 * * \\
(4.27)\end{array}$ & $\begin{array}{c}-4.83 \\
(8.97)\end{array}$ & $\begin{array}{c}8.44 * * \\
(4.14)\end{array}$ & $\begin{array}{l}-4.36 \\
(8.59)\end{array}$ \\
\hline$W_{2}$ & $\begin{array}{c}-0.14^{*} \\
(0.08)\end{array}$ & $\begin{array}{l}-011 \\
(0.14)\end{array}$ & $\begin{array}{l}-0.15 \\
(0.11)\end{array}$ & $\begin{array}{l}-0.12 \\
(0.14)\end{array}$ & $\begin{array}{l}-0.13 \\
(0.11)\end{array}$ \\
\hline$W_{l}$ & $\begin{array}{c}0.55 * * * \\
(0.07)\end{array}$ & $\begin{array}{c}0.58 * * * \\
(0.08)\end{array}$ & $\begin{array}{c}0.53 * * * \\
(0.13)\end{array}$ & $\begin{array}{c}0.59 * * * \\
(0.07)\end{array}$ & $\begin{array}{c}0.53 * * * \\
(0.13)\end{array}$ \\
\hline Prosocial & -- & -- & -- & $\begin{array}{l}4.09 * * \\
(1.67)\end{array}$ & $\begin{array}{l}-4.44 \\
(3.17)\end{array}$ \\
\hline Envy & -- & -- & -- & $\begin{array}{c}13.58 * * * \\
(2.49)\end{array}$ & $\begin{array}{c}2.63 \\
(9.51)\end{array}$ \\
\hline Period & $\begin{array}{c}0.54 \\
(0.73)\end{array}$ & $\begin{array}{c}-1.49 * * \\
(0.66)\end{array}$ & $\begin{array}{c}2.13 * * * \\
(0.34)\end{array}$ & $\begin{array}{c}-1.43 * * \\
(0.69)\end{array}$ & $\begin{array}{c}2.11 * * * \\
(0.32)\end{array}$ \\
\hline Period-squared & $\begin{array}{l}-0.03 \\
(0.03) \\
\end{array}$ & $\begin{array}{c}0.06 * * * \\
(0.02)\end{array}$ & $\begin{array}{c}-0.10 * * * \\
((0.01)\end{array}$ & $\begin{array}{c}0.06 * * * \\
(0.02)\end{array}$ & $\begin{array}{c}-0.10 * * * \\
(0.01)\end{array}$ \\
\hline No. Obs. & 1264 & 550 & 714 & 550 & 714 \\
\hline
\end{tabular}

$*, * *, * * *$ signify that coefficients are significantly different from zero at $10 \%, 5 \%$ and $1 \%$ levels. Regressions are Tobit regressions with robust standard errors adjusted for clustering on sessions in parentheses.

Regression (1) is the base regression that allows us to test predictions (a) and (b). The coefficient for $W_{1}$ is positive $(0.55)$ and significant with a p-value $<0.01$. This implies that a marginal increase in $W_{1}$ holding $W_{2}$ constant leads to a 0.55 increase in effort so we cannot reject prediction (a). This suggests that increasing the power of incentives by raising $W_{1}$ increases performance. We can test prediction (b) by examining the coefficient for $W_{2}$ which should be negative. While the coefficient is negative in regression (1) (-0.14), it is significant only at the $10 \%$ confidence level. The coefficient is not significant in the other regressions. Hence, the evidence in support of prediction (b) is weak. This suggests that a decrease in prize spread from increasing the loser's prize might not have a disincentive effect. One possible explanation is that perhaps there are social preferences (SP) at work which might result in reciprocity or gift-exchange toward principals that provide generous loser prizes. We can test this by comparing the Exogenous and Endogenous treatments. Charness (2004) suggests that causal attribution for a wage can affect whether a worker exhibits SP toward an employer. In the 
Endogenous treatment, agents know that they are dealing with human subjects assigned to be principals and thus there is scope for SP. Regressions (2) and (3) are identical to regression (1) except we have split the sample by treatment. We can see that estimating the regressions on each sub-sample has only minimal impact on the results.

We also did a robustness check on the impact of SP by creating variables from data obtained from the pre-tournament SP elicitation game. Similar to Bartling et al. (2009), subjects were asked to state whether they preferred option A or option B as in Table 3. Option A always yielded an even distribution of money ( $\$ 2$ to the decision maker and other player). Option B yielded uneven payoffs: in line $1(\$ 2, \$ 1)$, in line 2 $(3 \$, \$ 1)$, in line $3(2 \$, \$ 4)$, and in line $4(3 \$, \$ 5)$. We follow Bartling et al. to classify subjects into two SP categories. Prosocial types are interested in equal distributions even when they are ahead and always choose option A in the first two games. Envy types are averse to being behind and always choose equal distributions in the last two games.

Table 3: Social preferences games

\begin{tabular}{cccl}
\hline \hline No. & $\begin{array}{c}\text { Distribution } A \\
\text { Payoff to Self, Other }\end{array}$ & $\begin{array}{c}\text { Distribution } B \\
\text { Payoff to Self, Other }\end{array}$ & Game type \\
\hline 1 & $\$ 2, \$ 2$ & $\$ 2, \$ 1$ & Prosociality \\
2 & $\$ 2, \$ 2$ & $\$ 3, \$ 1$ & Costly Prosociality \\
3 & $\$ 2, \$ 2$ & $\$ 2, \$ 4$ & Envy \\
4 & $\$ 2, \$ 2$ & $\$ 3, \$ 5$ & Costly Envy \\
\hline
\end{tabular}

Regressions (4) and (5) in Table 2 are identical to regressions (2) and (3), except we also include dummy variables for Prosocial and Envy types. Once again, we see that controlling for SP has minimal impact on the estimated coefficients for $W_{1}$ and $W_{2}$ across subsamples. Thus, it does not appear that controlling for SP resolves the puzzle as to why a decrease in prize spread from increasing the loser's prize has little disincentive effect. Nevertheless, while controlling for SP does not appear to affect our tests of predictions (a) and (b), it is interesting to note that both Envy and Prosocial have direct positive effects on effort, but only in the Endogenous treatment (regression 4), which suggests that attribution of motives can "turn on" social preferences as Charness (2004) suggested. The positive coefficient for Prosocial makes intuitive sense since principals tend to do less well than agents and prosocial agents might help principals by exerting 
higher effort. The positive Envy coefficient is more surprising because there is no obvious reason why envy types, who are averse to being behind, would exert more effort with attribution. One possibility is that attribution "turns on" envy types' competitiveness so that they might exert more effort to win to avoid falling behind the other agent. However, even if true, the exact mechanism through which this occurs is unclear given that there are potentially complex SP dynamics between agents and principals and agents with each other, i.e. subjects in the role of agents may be comparing their relative position toward other agents and/or the principal.

We now turn to prediction (c), which states that effort should be non-increasing in $W_{2}$ holding prize spread constant. The regressions in Table 4 are identical to the regressions in Table 2 except $W_{1}-W_{2}$ replaces $W_{1}$, which holds prize spread constant. If the estimated coefficient for $W_{2}$ is non-positive, then this is consistent with prediction (c). However, the estimated coefficient of $W_{2}$ in the base regression (1) is positive (0.42) and significant at the $1 \%$ level. This is strong evidence against prediction (c). Separately

Table 4: Censored Regression for Effort

\begin{tabular}{|c|c|c|c|c|c|}
\hline & (1) & (2) & (3) & (4) & (5) \\
\hline & $\begin{array}{c}\text { All } \\
\text { Data }\end{array}$ & $\begin{array}{c}\text { Endogenous } \\
\text { Data }\end{array}$ & $\begin{array}{c}\text { Exogenous } \\
\text { Data }\end{array}$ & $\begin{array}{c}\text { Endogenous } \\
\text { Data }\end{array}$ & $\begin{array}{c}\text { Exogenous } \\
\text { Data }\end{array}$ \\
\hline Constant & $\begin{array}{c}1.65 \\
(5.49)\end{array}$ & $\begin{array}{c}10.09 * * \\
(4.27)\end{array}$ & $\begin{array}{c}-4.83^{*} \\
(6.79)\end{array}$ & $\begin{array}{c}8.44 * * \\
(4.14)\end{array}$ & $\begin{array}{l}-4.36 \\
(8.59)\end{array}$ \\
\hline$W_{2}$ & $\begin{array}{c}0.42^{* * * *} \\
(0.07)\end{array}$ & $\begin{array}{c}0.46^{* * *} \\
(0.08)\end{array}$ & $\begin{array}{c}0.38^{* * * *} \\
(0.10)\end{array}$ & $\begin{array}{c}0.47^{* * * *} \\
(0.08)\end{array}$ & $\begin{array}{c}0.40 * * * \\
(0.12)\end{array}$ \\
\hline$W_{1}-W_{2}$ & $\begin{array}{c}0.55^{* * * *} \\
(0.07)\end{array}$ & $\begin{array}{c}0.58^{* * *} \\
(0.08)\end{array}$ & $\begin{array}{c}0.53^{* * *} \\
(0.11)\end{array}$ & $\begin{array}{c}0.59 * * * \\
(0.07)\end{array}$ & $\begin{array}{c}0.53 * * * \\
(0.13)\end{array}$ \\
\hline Prosocial & -- & -- & -- & $\begin{array}{l}4.09 * * \\
(1.67)\end{array}$ & $\begin{array}{l}-4.44 \\
(3.17)\end{array}$ \\
\hline Envy & -- & -- & -- & $\begin{array}{c}13.58 * * \\
(2.49)\end{array}$ & $\begin{array}{c}2.63 \\
(9.51)\end{array}$ \\
\hline Period & $\begin{array}{c}0.54 \\
(0.73)\end{array}$ & $\begin{array}{c}-1.49 * * \\
(0.66)\end{array}$ & $\begin{array}{c}2.13 * * * \\
(0.34)\end{array}$ & $\begin{array}{c}-1.43 * * \\
(0.69)\end{array}$ & $\begin{array}{c}2.11 * * * \\
(0.32)\end{array}$ \\
\hline Period-squared & $\begin{array}{l}-0.03 \\
(0.03)\end{array}$ & $\begin{array}{c}0.06 * * * \\
(0.02)\end{array}$ & $\begin{array}{c}-0.10^{* * *} * \\
((0.01)\end{array}$ & $\begin{array}{c}0.06^{* * * *} \\
(0.02)\end{array}$ & $\begin{array}{c}-0.10^{* * *} * \\
(0.01)\end{array}$ \\
\hline No. Obs. & 1264 & 550 & 714 & 550 & 714 \\
\hline
\end{tabular}

$*, * *, * * *$ signify that coefficients are significantly different from zero at $10 \%, 5 \%$ and $1 \%$ levels. Regressions are Tobit regressions with robust standard errors adjusted for clustering on sessions in parentheses.

estimating the same regression on the Endogenous and Exogenous sub-samples had little impact on results ( 0.46 vs 0.38 ). Thus, attribution based SP does not explain our 
rejection of prediction (c). Regressions (4) and (5) provide another robustness check using Prosocial and Envy as regressors. Adding these control variables has minimal impact on the estimated coefficients for $W_{1}$ and $W_{1}-W_{2}$. Therefore, we can conclude with some confidence that we can reject prediction (c).

Finally, we turn to prediction (d) which states that an increase in either $W_{2}$ or $W_{1}$ $W_{2}$ (holding the other constant) should increase contract acceptance rates. Table 5 reports probit regressions where the dependent variable takes a value of " 1 " if an agent accepts and " 0 " otherwise. The reported coefficients are the marginal effects and their robust standard errors, adjusted for clustering on sessions, are reported in parentheses. Under prediction (d), the marginal effects for $W_{2}$ and $W_{1}-W_{2}$ should be positive. One can see from regression (1) that the estimated marginal effects for both of these variables are positive and significant at the $1 \%$ level. These results remain significant even after partitioning the sample into Endogenous (regression 2) and Exogenous (regression 3). The marginal effects are unaffected if we control for Prosocial and Envy (regressions 4 and 5). Thus, we cannot reject prediction (d). Note that the marginal effect of $W_{2}(0.02)$ is stronger than the marginal effect of $W_{1}-W_{2}(0.004$ to 0.006$)$. This is consistent with standard contract theory that suggests that the base pay is used to induce acceptance whereas wage variation is used to provide incentives.

Table 5: Probit Regressions of Contract Acceptance by Agents (Marginal Effects)

\begin{tabular}{|c|c|c|c|c|c|}
\hline & $(1)$ & (2) & (3) & (4) & $(5)$ \\
\hline & $\begin{array}{c}\text { All } \\
\text { Data }\end{array}$ & $\begin{array}{c}\text { Endogenous } \\
\text { Data }\end{array}$ & $\begin{array}{c}\text { Exogenous } \\
\text { Data }\end{array}$ & $\begin{array}{c}\text { Endogenous } \\
\text { Data }\end{array}$ & $\begin{array}{c}\text { Exogenous } \\
\text { Data }\end{array}$ \\
\hline$\overline{W_{2}}$ & $\begin{array}{c}0.02 * * * \\
(0.001)\end{array}$ & $\begin{array}{c}0.02 * * * \\
(0.002)\end{array}$ & $\begin{array}{c}0.02 * * * \\
(0.002)\end{array}$ & $\begin{array}{c}0.02 * * * \\
(0.002)\end{array}$ & $\begin{array}{r}0.02 * * * \\
(0.002)\end{array}$ \\
\hline$W_{1}-W_{2}$ & $\begin{array}{c}0.005^{* * * *} \\
(0.0009)\end{array}$ & $\begin{array}{c}0.006 * * * \\
(0.0006)\end{array}$ & $\begin{array}{l}0.004 * * \\
(0.002)\end{array}$ & $\begin{array}{c}0.006^{* * *} \\
(0.0006)\end{array}$ & $\begin{array}{c}0.004^{* *} \\
(0.002)\end{array}$ \\
\hline Prosocial & -- & -- & -- & $\begin{array}{c}0.04 \\
(0.07)\end{array}$ & $\begin{array}{l}-0.05 \\
(0.03)\end{array}$ \\
\hline Envy & -- & -- & -- & $\begin{array}{l}0.12 * * \\
(0.05)\end{array}$ & $\begin{array}{l}-0.02 \\
(0.10)\end{array}$ \\
\hline Period & $\begin{array}{l}0.007 * \\
(0.004)\end{array}$ & $\begin{array}{c}0.004 \\
(0.007)\end{array}$ & $\begin{array}{l}0.009 * * \\
(0.0046)\end{array}$ & $\begin{array}{c}0.005 \\
(0.008)\end{array}$ & $\begin{array}{l}0.01 * * \\
(0.004)\end{array}$ \\
\hline Period-squared & $\begin{array}{c}-0.0001 \\
(0.0002) \\
\end{array}$ & $\begin{array}{c}-0.0001 \\
(0.0003) \\
\end{array}$ & $\begin{array}{c}-0.0001 \\
((0.0001) \\
\end{array}$ & $\begin{array}{c}-0.0001 \\
(0.0003) \\
\end{array}$ & $\begin{array}{l}-0.0002^{*} \\
(0.0001) \\
\end{array}$ \\
\hline No. Obs. & 1920 & 960 & 960 & 960 & 960 \\
\hline
\end{tabular}




\section{Testing for Endogenous Prize Structures}

While $W_{1}$ and $W_{2}$ are exogenous to the agent, they are endogenous to principals as they are choice variables in the contract design problem. Proposition 3, combined with Proposition 4, allows us to derive a testable prediction about how prizes might change in response to agent's risk preferences. In particular, Proposition 4 predicts that, when a principal is contracting with more risk-averse agents, then the principal should implement a lower level of effort because risk aversion makes the principal's incentive cost function more convex. To accomplish this, the principal should reduce the prize spread $W_{1}-W_{2}$. Therefore, we expect the following key prediction to hold: an increase in agents' risk aversion will reduce the power of incentives, i.e. the prize spread.

To test this prediction, we use the risk elicitation data obtained prior to the tournament experiment. Our elicitation procedure followed Holt and Laury (2002) (HL), where subjects must choose between two lotteries as in Table 6. Option A is riskless, whereas Option B pays either $\$ 3$ or $\$ 0$. The probability of receiving $\$ 3, p_{B}$, is increasing as we move down the rows in Table 6. As $p_{B}$ increases, the expected payoff of Option B increases. A risk-neutral subject should choose Option A for the first six lines and then switch to Option B at the seventh line ( $\left.p_{B}=0.35\right)$. Risk-averse individuals should also

Table 6: Risk elicitatiom, expected payoffs and estimated risk aversion intervals

\begin{tabular}{|c|c|c|c|c|c|c|c|c|}
\hline \multicolumn{2}{|c|}{ Option A } & \multicolumn{4}{|c|}{ Option B } & \multirow[b]{2}{*}{$\mathrm{EPay}_{A}$} & \multirow[b]{2}{*}{$\mathrm{EPay}_{B}$} & \multirow[b]{2}{*}{ CRRA Interval } \\
\hline$p_{A}$ & $\$$ & $p_{B}$ & $\$$ & $1-p_{B}$ & $\$$ & & & \\
\hline 1 & $\$ 1$ & 0.05 & $\$ 3$ & 0.95 & $\$ 0$ & $\$ 1$ & $\$ 0.15$ & $-\infty,-1.73$ \\
\hline 1 & $\$ 1$ & 0.1 & $\$ 3$ & 0.10 & $\$ 0$ & $\$ 1$ & $\$ 0.30$ & $-1.73,-1.10$ \\
\hline 1 & $\$ 1$ & 0.15 & $\$ 3$ & 0.85 & $\$ 0$ & $\$ 1$ & $\$ 0.45$ & $-1.10,-0.73$ \\
\hline 1 & $\$ 1$ & 0.2 & $\$ 3$ & 0.80 & $\$ 0$ & $\$ 1$ & $\$ 0.60$ & $-0.73,-0.46$ \\
\hline 1 & $\$ 1$ & 0.25 & $\$ 3$ & 0.75 & $\$ 0$ & $\$ 1$ & $\$ 0.75$ & $-0.46,-0.26$ \\
\hline 1 & $\$ 1$ & 0.30 & $\$ 3$ & 0.70 & $\$ 0$ & $\$ 1$ & $\$ 0.90$ & $-0.26,-0.10$ \\
\hline 1 & $\$ 1$ & 0.35 & $\$ 3$ & 0.65 & $\$ 0$ & $\$ 1$ & $\$ 1.05$ & $-0.10,0.04$ \\
\hline 1 & $\$ 1$ & 0.40 & $\$ 3$ & 0.60 & $\$ 0$ & $\$ 1$ & $\$ 1.20$ & $0.04,0.17$ \\
\hline 1 & $\$ 1$ & 0.45 & $\$ 3$ & 0.65 & $\$ 0$ & $\$ 1$ & $\$ 1.35$ & $0.17,0.27$ \\
\hline 1 & $\$ 1$ & 0.50 & $\$ 3$ & 0.50 & $\$ 0$ & $\$ 1$ & $\$ 1.50$ & $0.27,0.37$ \\
\hline 1 & $\$ 1$ & 0.55 & $\$ 3$ & 0.45 & $\$ 0$ & $\$ 1$ & $\$ 1.65$ & $0.37,0.46$ \\
\hline 1 & $\$ 1$ & 0.60 & $\$ 3$ & 0.40 & $\$ 0$ & $\$ 1$ & $\$ 1.80$ & $0.46,0.54$ \\
\hline 1 & $\$ 1$ & 0.65 & $\$ 3$ & 0.35 & $\$ 0$ & $\$ 1$ & $\$ 1.95$ & $0.54,0.61$ \\
\hline 1 & $\$ 1$ & 0.70 & $\$ 3$ & 0.30 & $\$ 0$ & $\$ 1$ & $\$ 2.10$ & $0.61,0.68$ \\
\hline
\end{tabular}


eventually switch to Option B but only after choosing more lines of Option A. The point at which a subject switches depends on the degree of risk aversion. In the far right column, we report the interval for the coefficient of relative risk aversion that would rationalize switching from Option A to Option B. These coefficient intervals were derived under a CRRA utility $u(W)=\frac{W^{1-\delta}}{1-\delta}$. HL suggest that counting the total number of "safe" (Option A) choices per subject is an indicator of risk aversion. The median number in our experiment was 8 , which implies that the median subject falls in the CRRA interval 0.04 to 0.17 , which is a low degree of risk aversion, but this is not surprising given the low stakes in the risk elicitation game. Our CRRA utility should not be interpreted structurally, as we do not impose this utility on our data. We simply use it to give the reader something to anchor on when reading the risk table. The point is that an increase in the number of Option A choices should increase risk aversion regardless of the specific structure of risk preferences.

Table 7 on the next page reports six censored regressions used to test the hypothesis that the prize spread is decreasing in agent risk aversion. The data includes 456 observations from the Endogenous sessions on principal prize choices. ${ }^{12}$ The variables of interest are Avg Agent Risk (the average number of Option A choices made by the two agents contracting with a principal) and Lag Avg Agent Risk (a one period lag of Avg Agent Risk). Expecting the principal to know the risk preferences of agents ex ante (Avg Agent Risk) is a very demanding information requirement. ${ }^{13}$ Nevertheless, it is possible that the principal is capable of inferring risk preferences ex post (Lag Avg Agent Risk) based on decisions made by agents in a previous period, e.g. acceptance and performance outcomes. While this appears to be a quite challenging task, it should be borne in mind that there are only12 agents per session so the community of agents is

\footnotetext{
${ }^{12}$ Four Endogenous sessions with six principals per session and 19 periods (to account for one-period lag variables) equals 456.

${ }^{13}$ A stronger experimental design to test the effect of agents' risk aversion on principal's behavior would be to report both agents' lottery choices to the principal before he actually decided on the contract. Nevertheless, it's unlikely that in reality the principal receives this kind of information. Thus, we decided to test the predictions of the tournament theory in a more realistic setting, where the principal does not know the exact risk preferences of the agents but he can infer such preferences from previous interactions.
} 
Table 7: Censored Regression for Prize Spread $W_{1}-W_{2}$ by the Principal

\begin{tabular}{|c|c|c|c|c|c|c|}
\hline & (1) & (2) & (3) & (4) & (5) & (6) \\
\hline & $\begin{array}{c}\text { All } \\
\text { periods }\end{array}$ & $\begin{array}{c}\text { All } \\
\text { periods }\end{array}$ & $\begin{array}{c}\text { All } \\
\text { periods }\end{array}$ & $\begin{array}{c}\text { All } \\
\text { periods }\end{array}$ & $\begin{array}{c}\text { Periods } \\
1-10\end{array}$ & $\begin{array}{c}\text { Periods } \\
11-20\end{array}$ \\
\hline Constant & $\begin{array}{l}52.2 * * * \\
(12.50)\end{array}$ & $\begin{array}{c}43.76^{* * *} \\
(14.66)\end{array}$ & $\begin{array}{c}54.50 * * * \\
(13.12)\end{array}$ & $\begin{array}{c}46.16^{* * *} \\
(15.33)\end{array}$ & $\begin{array}{c}37.27 * * \\
(16.94)\end{array}$ & $\begin{array}{c}78.84^{*} \\
(0.37)\end{array}$ \\
\hline Principal Risk ${ }^{\mathrm{a}}$ & $\begin{array}{c}0.73 \\
(1.37)\end{array}$ & $\begin{array}{c}0.79 \\
(1.26)\end{array}$ & $\begin{array}{c}0.68 \\
(1.37)\end{array}$ & $\begin{array}{c}0.74 \\
(1.26)\end{array}$ & $\begin{array}{c}1.35 \\
(1.14)\end{array}$ & $\begin{array}{c}0.32 \\
(1.62)\end{array}$ \\
\hline Avg Agent Risk ${ }^{\mathrm{b}}$ & $\begin{array}{l}-0.21 \\
(0.78)\end{array}$ & $\begin{array}{l}-0.36 \\
(0.79)\end{array}$ & $\begin{array}{l}-0.27 \\
(0.80)\end{array}$ & $\begin{array}{l}-0.42 \\
(0.81)\end{array}$ & $\begin{array}{l}-0.003 \\
(1.14)\end{array}$ & $\begin{array}{c}0.32 \\
(1.62)\end{array}$ \\
\hline Lag Avg Agent Risk & $\begin{array}{l}-0.17 \\
(0.62)\end{array}$ & $\begin{array}{l}0.005 \\
(0.68)\end{array}$ & $\begin{array}{l}-0.25 \\
(0.64)\end{array}$ & $\begin{array}{l}-0.07 \\
(0.70)\end{array}$ & $\begin{array}{c}0.67 \\
(0.68)\end{array}$ & $\begin{array}{l}-0.71 \\
(1.39)\end{array}$ \\
\hline Lag Tournament Offer Rejected & -- & $\begin{array}{l}-0.33 \\
(1.68)\end{array}$ & -- & $\begin{array}{l}-0.46 \\
(1.69)\end{array}$ & $\begin{array}{l}-2.96^{*} \\
(1.64)\end{array}$ & $\begin{array}{c}1.56 \\
(2.71)\end{array}$ \\
\hline Lag Avg Output of Agents & -- & $\begin{array}{c}0.18 * * * \\
(0.04)\end{array}$ & -- & $\begin{array}{c}0.18 * * * \\
(0.04)\end{array}$ & $\begin{array}{c}0.04 \\
(0.09)\end{array}$ & $\begin{array}{c}0.30 * * * \\
(0.08)\end{array}$ \\
\hline Prosocial & -- & -- & $\begin{array}{l}-3.06 \\
(3.38)\end{array}$ & $\begin{array}{l}-3.34 \\
(3.12)\end{array}$ & $\begin{array}{l}-0.68 \\
(3.66)\end{array}$ & $\begin{array}{c}-5.38 * * \\
(2.67)\end{array}$ \\
\hline Envy & -- & -- & $\begin{array}{l}-3.20 \\
(1.96)\end{array}$ & $\begin{array}{l}-2.80 \\
(1.94)\end{array}$ & $\begin{array}{l}-3.71 \\
(3.63)\end{array}$ & $\begin{array}{l}-0.56 \\
(1.75)\end{array}$ \\
\hline Period & $\begin{array}{l}-1.47^{*} \\
(0.81)\end{array}$ & $\begin{array}{l}-1.22 \\
(0.74)\end{array}$ & $\begin{array}{l}-1.47^{*} \\
(0.81)\end{array}$ & $\begin{array}{l}-1.22 \\
(0.75)\end{array}$ & $\begin{array}{l}-1.69 \\
(1.83)\end{array}$ & $\begin{array}{l}-4.25 \\
(4.78)\end{array}$ \\
\hline Period-squared & $\begin{array}{c}0.06 \\
(0.04)\end{array}$ & $\begin{array}{c}0.06 \\
(0.04)\end{array}$ & $\begin{array}{c}0.06 \\
(0.04)\end{array}$ & $\begin{array}{c}0.06 \\
(0.04)\end{array}$ & $\begin{array}{c}0.10 \\
(0.15)\end{array}$ & $\begin{array}{c}0.16 \\
(0.16)\end{array}$ \\
\hline No. Obs. & 456 & 456 & 456 & 456 & 216 & 456 \\
\hline
\end{tabular}

$*, * *, * * *$ signify that coefficients are significantly different from zero at $10 \%, 5 \%$ and $1 \%$ levels.

Regressions are Tobit regressions with robust standard errors adjusted for clustering on sessions in parentheses. All data is from the Endogenous treatment. The dependent captures the endogenous prize spread chosen by principals.

${ }^{a}$ The risk variable measures the average number of Option A choices made by the two agents contracting with a principal in the risk elicitation game.

${ }^{b}$ Agent group average refers to average number of Option A choices made in the risk elicitation game by the two agents contracting with a principal. Thus, for each principal, there are 20 separate observations (one for each period) of group average risk per session.

fairly small. Given that there are 20 periods, each principal has ample opportunity to extrapolate the session group risk characteristics through observation of performance and acceptance decisions. Healy (2007) has shown that subjects are often able to infer information about group characteristics through stereotyping or other information.

To further control for the fact that principal may base current contracting decisions on previous experience, we also include in some regressions a dummy variable Lag Tournament Offer Rejected which takes a value of " 1 " if at least one of the two agents a principal contracted with in the previous period rejected his offer. In some regressions, we also include Lag Avg Output of Agents which is the average output (effort 
plus random shock) of the two agents that the principal contracted with. Additional controls include Risk, which is number of Option A choices made by the principal. Other controls are Prosocial, Envy, Period and Period-squared. We report six different regressions which include various combinations of control variables. Running multiple regressions allow us to examine the robustness of results. The last two regressions (5) and (6) also partition the sample into period 1-10 and 11-20.

We can see from Table 7 that Avg Agent Risk and Lag Avg Agent Risk had estimated coefficients that are not significant in any regression. Thus, the hypothesis that prize spread is decreasing in agent's risk aversion is rejected. It is possible that this "non result" can be attributed to principals having only a noisy ex post signal of agents' risk preferences. But it should be noted that if both principals and agents are risk-averse, then an increase in the principal's risk aversion should theoretically have a similar impact on prize spread as a decrease in the agent's risk aversion. Principals do know their own risk aversion and yet, the estimated coefficient for Principal Risk is also not significant. This lends more confidence to our result that prize spread does not respond to risk aversion. We will revisit this issue further after we provide a modified theory of tournaments based on relaxing the assumption of separable agent utility.

\section{An Interim Summary of Results and Empirical Puzzles}

So far, we have found mixed results concerning whether the data confirms the predictions of classic tournament theory. On the positive side, there is support for classic incentive effects in that raising the winner's prize increases effort. Also, an increase in either the loser's prize and/or prize spread increases participation. On the negative side, the following puzzles appear to contradict theory:

(1) Reducing prize spread by raising loser's prize (holding the winner's prize constant) does not appear to reduce effort. Moreover, if the loser's prize is raised while the prize spread is held constant, effort actually increases. 
(2) Principals make negative profits on average, and all joint profits go to agents. ${ }^{14}$ Given that rents primarily go to agents and the prize spread is lower than what is predicted under risk neutrality, this implies that the loser's prize is elevated relative to what canonical theory predicts.

(3) Principals do not appear to adjust their pay spread in response to agent's risk aversion as predicted by theory.

Controlling for SP did not explain the above puzzles. However, we did find that SP do have a direct impact on agent effort and therefore should be included as explanatory variables. In the remainder of the paper, we will show that the above puzzles can be explained by making a simple modification to the standard tournament model.

\section{Risk Aversion with Non-Separable Utility}

The assumption that agents' utility functions are separable in income and effort is pervasive in the literature and in textbook coverage of contract theory (Green and Stokey 1983; Bolton and Dewatripont 2005; Laffont and Martimort 2002). However, we will show that relaxing this assumption can yield qualitative predictions that can explain most of the behavior in our experiment. It is important to emphasize that non-separable utility is the appropriate assumption for situations in which effort cost is measured in monetary units rather than disutility units. We believe that this covers a wide range of real world situations since most production environments often require agents or suppliers to make costly expenditures and investments. The non-separability assumption should also apply to our experiment (and many other previously conducted chosen-effort experiments) since effort is a direct monetary cost.

To show the impact of non-separability on agent behavior, we begin by noting that the expected payoff for a risk-averse agent with non-separable utility is given by

$$
E\left(U\left(\pi_{i}^{A}\right)\right)=p_{i} u\left[W_{1}-c\left(e_{i}\right)\right]+\left(1-p_{i}\right) u\left[W_{2}-c\left(e_{i}\right)\right] .
$$

\footnotetext{
${ }^{14}$ Although not reported, we checked the robustness of this result and ran additional treatment raising the principal's reservation utility from zero to 15 . Agents still grabbed all of the surplus, leaving principles with negative expected payoff.
} 
If the agent is risk-averse so that $u(\bullet)$ is strictly concave, then the agent's marginal disutility/cost of effort is $\left\{p_{i} u^{\prime}\left[W_{1}-c\left(e_{i}\right)\right]+\left(1-p_{i}\right) u^{\prime}\left[W_{2}-c\left(e_{i}\right)\right]\right\} c^{\prime}(e)$. With separable utility, the same marginal disutility/cost is $c^{\prime}(e)$. Hence, the difference is that $c^{\prime}(e)$ is multiplied by a probability weighted linear combination of marginal utilities under nonseparability. This produces two non-trivial implications. First, since exerting effort reduces wealth, which increases $u^{\prime}(\bullet)$, non-separability potentially magnifies the marginal cost of effort. One way to offset this is to raise the agent's wealth via the prizes. If the agent is very risk-averse so that marginal utility changes rapidly with wealth, then it may be cheaper for the principal to provide incentives by raising wealth rather than by increasing the prize spread. If the agent is sufficiently risk-averse, then his wealth may have to be raised to the point of leaving him with rents (Laffont and Martimort 2002). ${ }^{15}$ One implication of this is that an increase in agent's risk aversion may no longer unambiguously predict a decrease in prize spread. Second, since the utility function is concave, it follows that $u^{\prime}\left(W_{2}\right)>u^{\prime}\left(W_{1}\right)$. Hence, if incentives must be provided by raising wealth, more can be accomplished by raising $W_{2}$ rather than $W_{1}$. With sufficient risk aversion, the qualitative implications are very similar to the qualitative predictions of gift-exchange where raising an agent's payoff can induce higher effort (Akerlof 1982; Fehr, Kirchsteiger, and Riedl 1993). But whereas gift-exchange relies on other-regarding preferences, our model assumes that the agent is strictly self-interested. In short, nonseparability can dramatically impact even qualitative predictions.

\section{A. Analysis of Incentives with Non-Separable Utility.}

We now generate comparative statics predictions under the assumption that agent's utility is non-separable. The reaction function of (5) is given by

$$
p_{i e}\left\{u\left[W_{1}-c\left(e_{i}\right)\right]-u\left[W_{2}-c\left(e_{i}\right)\right]\right\}=\left\{p_{i} u^{\prime}\left[W_{1}-c\left(e_{i}\right)\right]+\left(1-p_{i}\right) u^{\prime}\left[W_{2}-c\left(e_{i}\right)\right]\right\} c^{\prime}(e) .
$$

\footnotetext{
${ }^{15}$ See section 5.3 in Laffont and Martimort (2002) for a discussion of contracting under non-separability.
} 
We can use (6) to conduct comparative statics analysis of how the agent will respond to changes in the tournament prizes. We also suppress the subscript $i$ so that $p_{i e}=p_{e}$ to simplify notation. ${ }^{16}$

Proposition 5: A risk-averse agent with non-separable utility optimally responds to a change in tournament prize structure as follows:

a) Effort increases with an increase in $W_{1}$ holding $W_{2}$ constant;

b) If the agent's coefficient of absolute risk aversion $r_{A}\left(W_{2}-c(e)\right) \geq \frac{p_{e}}{c^{\prime}(e)\left(1-p_{i}\right)}$ then effort is non-decreasing in $W_{2}$ holding $W_{1}$ constant;

c) If $r_{A}\left(W_{2}-c(e)\right) \geq \frac{p_{e}}{c^{\prime}(e)\left(1-p_{i}\right)}-\frac{u^{\prime}\left[W_{1}-c(e)\right]}{u^{\prime}\left[W_{2}-c(e)\right]} \frac{\left[p_{e}+p r_{A}\left(W_{1}-c(e)\right) c^{\prime}(e)\right]}{(1-p) c^{\prime}(e)}$, then effort is increasing in $W_{2}$ holding the prize spread constant;

d) An increase in either $W_{1}$ or $W_{2}$ (holding the other constant) relaxes agents' participation constraint and induces more participation.

Predictions (b) and (c) of Proposition 5 that are based on non-separable utility differ from earlier predictions of Propositions 1 and 2 that are based on separable utility. In fact, Proposition 5 generates an even more refined prediction which is that the qualitative response of effort to $W_{2}$ is not unambiguous but depends on the size of the coefficient of absolute risk aversion. That is, for sufficiently risk-averse agents, raising $W_{2}$ can provide incentives by lowering marginal effort cost. Therefore, prediction (b) can explain one of our puzzles because it suggests that effort does not have to decrease if the prize spread is reduced by raising $W_{2}$. Prediction (c) is similar but applies if the prize spread is held constant. If agents are risk-averse enough, then increasing $W_{2}$ can increase effort. Part (d) is identical to part (d) in Propositions 1 and 2; thus, we will not analyze this last prediction further for the remainder of the paper.

To test Proposition 5, we report the results of a new set of regressions in Table 8 on page 27. We use Risk as a regressor since parts (b) and (c) state that effort response to $W_{2}$ depends on risk preferences. We also interact $W_{2}$ with $\left(\right.$ Risk-Risk $\left.{ }^{*}\right)$, where $R i s k^{*}$ is a

\footnotetext{
${ }^{16}$ In a symmetric equilibrium, $p_{i e}=p_{j e}=p_{e}$.
} 
specific number of Option As chosen. For example, if Risk $^{*}=7$, then $\left(\right.$ Risk- Risk $\left.^{*}\right)=$ (Risk-7) and the interaction term is $W_{2} \times($ Risk-7). Adding this interaction term means that the coefficient for $W_{2}$ captures the marginal response of effort to $W_{2}$ at Risk $=7$. To see this, note that the total marginal response is the sum of the coefficients for $W_{2}$ and $W_{2} \times\left(\right.$ Risk-7). But when evaluated at Risk $=7, W_{2} \times($ Risk-7 $)=0$. Thus, by estimating different regressions with different values for Risk ${ }^{*}$ in the interaction term, the coefficient for $W_{2}$ can capture the marginal response of effort to $W_{2}$ across a range of risk aversion levels. If the theory is correct, regression analysis can reveal the critical risk thresholds that would cause effort response to $W_{2}$ to become non-decreasing (under prediction (b)) or increasing (under prediction (c)). Moreover, the coefficient for $W_{2}$ ought to become less negative as we increase Risk $^{*}$ in the interaction term. Similarly, if prediction (c) is correct, we ought to observe a positive response of effort to $W_{2}$ as we increase Risk ${ }^{*}$.

Regressions (1) through (4) in Table 8 on the next page can be used to test prediction (b) because we include $W_{1}$ and $W_{2}$ as regressors. Under prediction (b) we expect effort to be decreasing in $W_{2}$ when agents are not very risk-averse, but to become non-decreasing once agents are risk-averse enough. Indeed, for low levels of Risk ${ }^{*}$, the estimated coefficient for $W_{2}$ is negative and significant. At higher levels of Risk ${ }^{*}$, the coefficient is not significant. Specifically, note that regression (1) involves the interaction term $W_{2} \times\left(\right.$ Risk-7), regression (2) the term $W_{2} \times($ Risk-8), regression (3) the term $W_{2} \times\left(\right.$ Risk-9), and regression (4) the term $W_{2} \times\left(\right.$ Risk-10). ${ }^{17}$ Thus, we are estimating effort response to $W_{2}$ at increasing levels of risk aversion as we move from regression (1) to (4). The estimated coefficient for $W_{2}$ of -0.22 in regression (1) tells us that, for subjects that behaved as if they were approximately risk-neutral in the risk elicitation game, a marginal increase in $W_{2}$ resulted in a 0.22 decrease in effort. However, in regression (2), this same coefficient declines to -0.17 for subjects that exhibit more risk aversion. This coefficient declines further in regression (3) to -0.11 and is no longer significant. Thus, the threshold at which the estimated coefficient switches from negative to insignificant appears to be at

\footnotetext{
${ }^{17}$ Although we also estimated regressions for interaction terms that involved Risk $^{*}<7$ and Risk $^{*}>10$, we did not report the results since they only confirmed the patterns observed in the four regressions we did report.
} 
Risk $^{*}=9$. In regression (4) we see the pattern continue as the coefficient declines to 0.05 for Risk $^{*}=10$. Overall, these results are remarkably consistent with part (b) of Proposition 5 and provide a compelling explanation for one of our earlier puzzles.

Table 8: Censored Regression for Effort

\begin{tabular}{|c|c|c|c|c|c|c|c|c|}
\hline & (1) & (2) & (3) & (4) & $(5)$ & $(6)$ & $(7)$ & $(8)$ \\
\hline Constant & $\begin{array}{l}24.10^{*} \\
(14.45)\end{array}$ & $\begin{array}{l}24.10^{*} \\
(14.45)\end{array}$ & $\begin{array}{l}24.10^{*} \\
(14.45)\end{array}$ & $\begin{array}{l}24.10^{*} \\
(14.45)\end{array}$ & $\begin{array}{l}24.10^{*} \\
(14.45)\end{array}$ & $\begin{array}{l}24.10^{*} \\
(14.45)\end{array}$ & $\begin{array}{l}24.10^{*} \\
(14.45)\end{array}$ & $\begin{array}{l}24.10^{*} \\
(14.45)\end{array}$ \\
\hline$W_{2}$ & $\begin{array}{c}-0.22 * * * \\
(0.08)\end{array}$ & $\begin{array}{c}-0.17 * * \\
(0.07)\end{array}$ & $\begin{array}{l}-0.11 \\
(0.08)\end{array}$ & $\begin{array}{l}-0.05 \\
(0.11)\end{array}$ & $\begin{array}{c}0.17 \\
(0.21)\end{array}$ & $\begin{array}{c}0.22 \\
(0.17)\end{array}$ & $\begin{array}{l}0.28 * * \\
(0.13)\end{array}$ & $\begin{array}{c}0.33 * * * \\
(0.10)\end{array}$ \\
\hline$W_{l}$ & $\begin{array}{c}0.55 * * * \\
(0.07)\end{array}$ & $\begin{array}{c}0.55 * * * \\
(0.07)\end{array}$ & $\begin{array}{c}0.55 * * * \\
(0.07)\end{array}$ & $\begin{array}{c}0.55^{* * *} \\
(0.07)\end{array}$ & -- & -- & -- & -- \\
\hline$\left(W_{1}-W_{2}\right)$ & -- & -- & -- & -- & $\begin{array}{c}0.55^{* * * *} \\
(0.07)\end{array}$ & $\begin{array}{c}0.55^{* * * *} \\
(0.07)\end{array}$ & $\begin{array}{c}0.55^{* * *} \\
(0.07)\end{array}$ & $\begin{array}{c}0.55^{* * * *} \\
(0.07)\end{array}$ \\
\hline Risk & $\begin{array}{c}-2.58^{* * *} \\
(1.23)\end{array}$ & $\begin{array}{c}-2.58^{* * *} \\
(1.23)\end{array}$ & $\begin{array}{c}-2.58^{*} \\
(1.23)\end{array}$ & $\begin{array}{l}-2.58^{*} \\
(1.23)\end{array}$ & $\begin{array}{l}-2.58^{*} \\
(1.23)\end{array}$ & $\begin{array}{l}-2.58^{*} \\
(1.23)\end{array}$ & $\begin{array}{l}-2.58^{*} \\
(1.23)\end{array}$ & $\begin{array}{l}-2.58^{*} \\
(1.23)\end{array}$ \\
\hline$W_{2} \times(R i s k-4)$ & -- & -- & -- & -- & $\begin{array}{c}0.06 \\
(0.04)\end{array}$ & -- & -- & -- \\
\hline$W_{2} \times($ Risk-5) & -- & -- & -- & -- & -- & $\begin{array}{c}0.06 \\
(0.04)\end{array}$ & -- & -- \\
\hline$W_{2} \times($ Risk-6) & -- & -- & -- & -- & -- & -- & $\begin{array}{c}0.06 \\
(0.04)\end{array}$ & -- \\
\hline$W_{2} \times(R i s k-7)$ & $\begin{array}{c}0.06 \\
(0.04)\end{array}$ & -- & -- & -- & -- & -- & -- & $\begin{array}{c}0.06 \\
(0.04)\end{array}$ \\
\hline$W_{2} \times(R i s k-8)$ & -- & $\begin{array}{c}0.06 \\
(0.04)\end{array}$ & -- & -- & -- & -- & -- & -- \\
\hline$W_{2} \times($ Risk-9) & -- & -- & $\begin{array}{c}0.06 \\
(0.04)\end{array}$ & -- & -- & -- & -- & -- \\
\hline$W_{2} \times($ Risk-10) & -- & -- & -- & $\begin{array}{c}0.06 \\
(0.04)\end{array}$ & -- & -- & -- & -- \\
\hline Prosocial & $\begin{array}{l}-0.58 \\
(1.85)\end{array}$ & $\begin{array}{l}-0.58 \\
(1.85)\end{array}$ & $\begin{array}{l}-0.58 \\
(1.85)\end{array}$ & $\begin{array}{l}-0.58 \\
(1.85)\end{array}$ & $\begin{array}{l}-0.58 \\
(1.85)\end{array}$ & $\begin{array}{l}-0.58 \\
(1.85)\end{array}$ & $\begin{array}{l}-0.58 \\
(1.85)\end{array}$ & $\begin{array}{l}-0.58 \\
(1.85)\end{array}$ \\
\hline Envy & $\begin{array}{c}3.19 \\
(6.08)\end{array}$ & $\begin{array}{c}3.19 \\
(6.08)\end{array}$ & $\begin{array}{c}3.19 \\
(6.08)\end{array}$ & $\begin{array}{c}3.19 \\
(6.08)\end{array}$ & $\begin{array}{c}3.19 \\
(6.08)\end{array}$ & $\begin{array}{c}3.19 \\
(6.08)\end{array}$ & $\begin{array}{c}3.19 \\
(6.08)\end{array}$ & $\begin{array}{c}3.19 \\
(6.08)\end{array}$ \\
\hline No. Obs. & 1264 & 1264 & 1264 & 1264 & 1264 & 1264 & 1264 & 1264 \\
\hline
\end{tabular}

Regressions (5) through (8) in Table 8 are identical to (1) through (4) except $W_{1}$ is replaced with $W_{1}-W_{2}$ in order to hold the prize spread constant. This allows us to examine prediction (c) of Proposition 5. Like prediction (b), prediction (c) states that effort response to $W_{2}$ depends on agents' risk aversion exceeding a threshold level. Prediction (c) is even stronger than (b) in that it suggests that effort is not just nondecreasing but responds positively to an increase in $W_{2}$ and at a lower risk threshold. 
Intuitively, when we hold $W_{1}$ constant, an increase in $W_{2}$ reduces the marginal disutility of effort but it also reduces the prize spread. However, if we hold prize spread constant, then we are holding marginal revenue to the agent constant while lowering marginal disutility of effort. Hence, less curvature is needed to observe a positive effort response to $W_{2}$. The threshold in prediction (c) of Proposition 5 is directly comparable to the threshold for prediction (b); we can see that it is the same threshold minus the term

$$
\frac{u^{\prime}\left[W_{1}-c(e)\right]}{u^{\prime}\left[W_{2}-c(e)\right]} \frac{\left[p_{e}+p r_{A}\left(W_{1}-c(e)\right) c^{\prime}(e)\right]}{(1-p) c^{\prime}(e)},
$$

which is clearly positive. Hence, a lower risk threshold is needed for part (c).

Under prediction (c), we expect the marginal responses of effort to $W_{2}$ to increase in magnitude for increasing levels of risk aversion. Moreover, once we obtain the marginal response estimates for various levels of risk aversion, we should be able to identify the risk threshold at which the response changes from zero to positive. Under prediction (c), this threshold should be smaller than the threshold under prediction (b). We can see from regressions (5)-(8) that the estimated coefficients for $W_{2}$ are again remarkably consistent with the theory. First, the marginal response of effort to $W_{2}$ increases as we move from regression (5) to regression (8), which is exactly what the theory predicts. Second, it appears that the risk threshold at which the estimated marginal response changes from zero to positive is at $R i s k^{*}=6$. To see this, note that the estimated coefficient for $W_{2}$ is 0.22 , but not significantly different from zero in regression (6) where Risk $^{*}=5$. This coefficient increases to 0.28 and becomes significant in regression (7) where $R_{i s} k^{*}=6$. This is lower than the threshold we estimated to test prediction (b) which was at $R i s k^{*}=9$. Thus, it appears that the non-separable utility model does a remarkable job of resolving some of our earlier puzzles with respect to the incentive effect of $W_{2}$.

With regard to prediction (a), we see that the estimated coefficients for $W_{1}$ are 0.55 and significantly different from zero across all regressions. These results are very similar to earlier results so we will not dwell on them except to say that the positive impact of increasing $W_{1}$ on effort appears to be very robust. 


\section{B. Optimal Contracting with Risk Aversion and Non-Separable Utility}

We now revisit the principal's tournament design problem. Recall that under separability, the only way to provide incentives to agents is to increase the prize spread. When the agent is risk-averse, the principal is forced into a tradeoff between risk and incentives and therefore greater agent risk aversion will result in a reduction in the prize spread. However, with non-separable utility, incentives can be provided either by increasing the agent's marginal revenue (the prize spread) or reducing the agent's marginal cost of effort by raising $W_{2}$. Hence, we show that an increase in risk aversion no longer provides an unambiguous prediction about prize spread, although we do show that an increase in agent risk aversion results in the principal raising the level of $W_{2}$ so long as the coefficient of absolute risk aversion does not decline too rapidly with wealth. ${ }^{18}$ The non-separable model can thus resolve two more of our earlier puzzles.

To show this formally, consider the principal's design problem.

$$
\begin{gathered}
\max _{W_{1}, W_{2} ; e} 2\left[e-p_{i}\left(W_{1}+W_{2}\right)\right] \quad \text { s.t. } \\
p_{i} u\left[W_{1}-c\left(e_{i}\right)\right]+\left(1-p_{i}\right) u\left[W_{2}-c\left(e_{i}\right)\right] \geq v \text { (participation constraint) } \\
\frac{\partial p_{i}}{\partial e_{i}}\left\{u\left[W_{1}-c\left(e_{i}\right)\right]-u\left[W_{2}-c\left(e_{i}\right)\right]\right\}-\left\{p_{i} u^{\prime}\left[W_{1}-c\left(e_{i}\right)\right]+\left(1-p_{i}\right) u^{\prime}\left[W_{2}-c\left(e_{i}\right)\right]\right\} c^{\prime}(e) \geq 0 \text { (incentive cstr.) }
\end{gathered}
$$

Letting $\lambda$ and $\mu$ be the langrange multipliers for the participation and incentive compatibility constraints, respectively, the first order conditions can be written as

$$
\begin{array}{ll}
W_{1}: & \frac{2 p_{i}}{u^{\prime}\left[W_{1}-c\left(e_{i}\right)\right]}=p_{i} \lambda+\mu\left[\frac{\partial p_{i}}{\partial e_{i}}+p_{i} r_{A}\left[W_{1}-c\left(e_{i}\right)\right] c^{\prime}\left(e_{i}\right)\right] \\
W_{2}: & \frac{2 p_{i}}{u^{\prime}\left[W_{2}-c\left(e_{i}\right)\right]}=\left(1-p_{i}\right) \lambda+\mu\left[-\frac{\partial p_{i}}{\partial e_{i}}+\left(1-p_{i}\right) r_{A}\left[W_{2}-c\left(e_{i}\right)\right] c^{\prime}\left(e_{i}\right)\right] \\
\lambda: & p_{i} u\left[W_{1}-c\left(e_{i}\right)\right]+\left(1-p_{i}\right) u\left[W_{2}-c\left(e_{i}\right)\right] \geq v, \\
\mu: & p_{i e}\left\{u\left[W_{1}-c\left(e_{i}\right)\right]-u\left[W_{2}-c\left(e_{i}\right)\right]\right\}-\left\{p_{i} u^{\prime}\left[W_{1}-c\left(e_{i}\right)\right]+\left(1-p_{i}\right) u^{\prime}\left[W_{2}-c\left(e_{i}\right)\right]\right\} c^{\prime}(e)=0 .
\end{array}
$$

The first order conditions (9)-(12) are too complex to yield closed form solutions for optimal contract terms. Nonetheless, we can conduct comparative statics analysis to

\footnotetext{
${ }^{18}$ For example, this would be satisfied with CARA. It will also be satisfied for DARA so long as DARA is not too rapid.
} 
get qualitative insights into how the principal might optimally change tournament prizes in response to agent risk aversion. This can lead to qualitative predictions about why, for instance, a principal might offer a high $W_{2}$ relative to the separable utility cases and why the principal might leave the agent with rents.

Proposition 6: When agents have non-separable utility and if the coefficient of absolute risk aversion is large enough, then under the optimal contract:

a) the participation constraint is not binding and the agent earns rents; and

b) even if the agent's participation constraint is not binding, the incentive compatibility constraint is still binding.

Part (a) states that, with low agent's risk aversion, the participation constraint binds and the principal does not leave the agent with rents. However, as risk aversion increases, the principal may raise $W_{2}$ to reduce the marginal disutility of effort, which should leave the agent with rents. Part (b) states that if the agent is left with rents under the optimal contract, then the incentive compatibility constraint still binds. ${ }^{19}$ Proposition 6 is useful because it identifies the important binding constraints for subsequent comparative static analysis and explains why agents might earn significant rents.

The next set of comparative statics can provide insights into when an increase in risk aversion should induce a principal to increase $W_{2}$ and/or reduce $W_{1}$.

Corollary 1: Suppose that the agent's participation constraint does not bind and that the necessary and sufficient conditions for the principal's profit maximizing tournament design problem are satisfied. Then the following describes how a change in the coefficient of absolute risk aversion affects the principal's prize choices:

a) $\quad W_{2}$ increases with a marginal increase in the agent's coefficient of absolute risk aversion (across all income levels) if and only if

$$
r_{A}\left[W_{2}-c(e)\right]-r_{A}\left[W_{1}-c(e)\right]<\frac{p_{e}}{p(1-p) c^{\prime}(e)}
$$

\footnotetext{
${ }^{19}$ Even if the risk aversion is low enough so that the agent's participation constraint will bind, the incentive compatibility constraint will still bind if the agent's utility function does not exhibit severe decreasing absolute risk aversion (DARA). We omit the proof and do not analyze the binding participation constraint case because it closely approximates the separable utility case and will not serve to explain the puzzles observed in our experimental data.
} 
b) $\quad W_{1}$ decreases with a marginal increase in the agent's coefficient of absolute risk aversion (across all income levels) if and only if either (i) $r_{A}\left[W_{2}-c(e)\right]>\frac{p_{e}}{(1-p) c^{\prime}(e)}$

$$
\begin{aligned}
& \text { and } r_{A}\left[W_{2}-c(e)\right]-r_{A}\left[W_{1}-c(e)\right]<\frac{p_{e}}{p(1-p) c^{\prime}(e)} \text {, or }(i i) r_{A}\left[W_{2}-c(e)\right]<\frac{p_{e}}{(1-p) c^{\prime}(e)} \text { and } \\
& r_{A}\left[W_{2}-c(e)\right]-r_{A}\left[W_{1}-c(e)\right]>\frac{p_{e}}{p(1-p) c^{\prime}(e)} .
\end{aligned}
$$

Corollary 1 provides conditions under which theory can be consistent with principals endogenously increasing $W_{2}$ and/or reducing $W_{1}$ in response to an increase in agent risk aversion. If $W_{2}$ increases and $W_{1}$ decreases, then we also get prize compression in response to an increase in agent risk aversion, which is the standard prediction in the literature. Other possibilities for prize compression to occur are for $W_{1}$ to increase but at a slower rate than $W_{2}$ or for $W_{1}$ to decrease at a faster rate than $W_{2}$. However, it is obvious from Corollary 1 that the conditions for $W_{1}$ and $W_{2}$ to move in the right direction to ensure prize compression are stringent. For example, if $r_{A}\left[W_{2}-c(e)\right]>\frac{p_{e}}{(1-p) c^{\prime}(e)}$ and $r_{A}\left[W_{2}-c(e)\right]-r_{A}\left[W_{1}-c(e)\right]>\frac{p_{e}}{p(1-p) c^{\prime}(e)}$, then an increase in agent risk aversion would cause the principal to lower $W_{2}$ and raise $W_{1}$ thereby increasing the prize spread. In short, the unambiguous prediction that the optimal prize spread is decreasing in agent risk aversion no longer holds.

The cleanest prediction that Corollary 1 yields is for $W_{2}$ to increase in agent risk aversion. The only requirement is for $r_{A}\left[W_{2}-c(e)\right]-r_{A}\left[W_{1}-c(e)\right]<\frac{p_{e}}{p(1-p) c^{\prime}(e)}$; i.e. the degree of decreasing absolute risk aversion (DARA) is not too severe. Intuitively, when agents are risk-averse, the principal might consider raising $W_{2}$ to decrease the agent's marginal disutility of effort. But if DARA is severe so that agents are much less risk-averse at $W_{1}$ than at $W_{2}$, then raising $W_{1}$ can reduce the agent's risk premium, which can reduce the cost of using the prize spread for incentive provision. Hence, with severe 
DARA, increasing the prize spread might be more cost effective to the principal than raising $W_{2}$ and leaving rents. Although the degree of DARA is ultimately an empirical question, the prediction is still useful because it implies that observing a principal raising $W_{2}$ in response to agent risk aversion crossing certain thresholds is consistent with theory. Moreover, it seems plausible that the degree of DARA will be mild over the income range in our experiments.

The regressions in Table 9 are similar to those in Table 7 except the dependent variable is now $W_{2}$. We also include some additional measures of avg group risk for each pair of agents who contracted with the principal. Dummy 6-8 is a dummy variable that equals " 1 " if the two-agent group avg number of Option A choices is between 6 and 8

Table 9: Censored Regressions for $W_{2}$ chosen by the Principal

\begin{tabular}{|c|c|c|c|c|}
\hline & $(1)$ & $(2)$ & $(3)$ & $(4)$ \\
\hline Dependent Variable & $\begin{array}{c}W_{2} \\
\text { All periods }\end{array}$ & $\begin{array}{c}W_{2} \\
\text { All periods }\end{array}$ & $\begin{array}{c}W_{2} \\
\text { Periods } 1-10\end{array}$ & $\begin{array}{c}W_{2} \\
\text { Periods } 11-20\end{array}$ \\
\hline Constant & $\begin{array}{c}12.95 * * \\
(5.21)\end{array}$ & $\begin{array}{c}16.92 * * * \\
(5.91)\end{array}$ & $\begin{array}{c}24.82 * * * \\
(7.58)\end{array}$ & $\begin{array}{c}24.31 * * * \\
(8.54)\end{array}$ \\
\hline Principal Risk & $\begin{array}{l}-0.52 \\
(0.43)\end{array}$ & $\begin{array}{l}-0.52 \\
(0.41)\end{array}$ & $\begin{array}{c}-1.23 * * * \\
(0.29)\end{array}$ & $\begin{array}{c}0.02 \\
(0.54)\end{array}$ \\
\hline Avg Agent Risk & $\begin{array}{c}0.30 \\
(0.32)\end{array}$ & -- & -- & -- \\
\hline Lag Avg Agent Risk & $\begin{array}{c}0.51 \\
(0.34)\end{array}$ & & & \\
\hline $\begin{array}{l}\text { Dummy 6-8 } \\
\text { (1 if Avg Agent Risk between 6-8) }\end{array}$ & -- & $\begin{array}{l}1.85 * * \\
(0.76)\end{array}$ & $\begin{array}{l}-0.45 \\
(1.58)\end{array}$ & $\begin{array}{l}4.60 * * * \\
(0.98)\end{array}$ \\
\hline $\begin{array}{l}\text { Dummy 9-15 } \\
\text { (1 if Avg Agent Risk between 9-15) }\end{array}$ & -- & $\begin{array}{l}2.52 * * * \\
(0.60)\end{array}$ & $\begin{array}{c}0.58 \\
(1.53)\end{array}$ & $\begin{array}{l}5.12 * * * \\
(1.49)\end{array}$ \\
\hline Lag Dummy 6-8 & -- & $\begin{array}{c}0.47 \\
(0.62)\end{array}$ & $\begin{array}{l}-0.80 \\
(2.03)\end{array}$ & $\begin{array}{c}1.02 \\
(2.17)\end{array}$ \\
\hline Lag Dummy 9-15 & -- & $\begin{array}{l}1.70 * * \\
(0.81)\end{array}$ & $\begin{array}{l}-1.11 \\
(1.87)\end{array}$ & $\begin{array}{l}3.99 * \\
(2.23)\end{array}$ \\
\hline Lag Tournament Offer Rejected & $\begin{array}{c}0.85 * * \\
(0.39)\end{array}$ & $\begin{array}{c}0.97 * * \\
(0.46)\end{array}$ & $\begin{array}{l}5.75 * * \\
(2.59)\end{array}$ & $\begin{array}{c}-2.96 * * \\
(1.19)\end{array}$ \\
\hline LagAvg Output of Agents & $\begin{array}{l}0.08 * * * \\
(0.009)\end{array}$ & $\begin{array}{c}0.08 * * * \\
(0.008)\end{array}$ & $\begin{array}{c}0.13 * * \\
(0.06)\end{array}$ & $\begin{array}{c}0.03 \\
(0.04)\end{array}$ \\
\hline Prosocial & $\begin{array}{l}-1.61 \\
(1.30)\end{array}$ & $\begin{array}{l}-1.68 \\
(1.28)\end{array}$ & $\begin{array}{l}-2.32 \\
(2.45)\end{array}$ & $\begin{array}{l}-1.10 \\
(1.27)\end{array}$ \\
\hline Envy & $\begin{array}{c}6.42 * * * \\
(0.98)\end{array}$ & $\begin{array}{c}6.10 * * * \\
(1.03)\end{array}$ & $\begin{array}{c}7.53 * * * \\
(2.75)\end{array}$ & $\begin{array}{c}4.27 * * * \\
(0.95)\end{array}$ \\
\hline No. Obs. & 456 & 456 & 216 & 240 \\
\hline
\end{tabular}


inclusive. Dummy 9-15 equals " 1 " if the group avg number of Option A choices is between 9 and 15 inclusive. We replace Avg Agent Risk with these dummies in some regressions because, according to Proposition 5, the response of effort to $W_{2}$ depends on risk thresholds and may not depend continuously on risk aversion. Moreover, the results from Table 8 suggest that agent behavior changed qualitatively when jumping from 5 to 6 Option A choices and when jumping from 8 to 9 Option A choices. Dummy 6-8 and Dummy 9-15 were defined with these empirical thresholds in mind so these dummies might be important for predicting principals' choice of $W_{2}$ since an optimizing principal should anticipate agent responses.

Our base regression (1) uses the Avg Agent Risk variable and its lag as regressors just as in Table 7. Neither coefficient is significant. However, in regression (2), we see that the coefficient for Dummy 6-8 is positive (1.85) and significant at the 5\% level. Moreover, the coefficient for Dummy 9-15 is even larger (2.52) and significant at the 1\% level. The omitted category includes those agents that yield a group avg of less than 6 Option A choices. Fewer than 6 Option A choices is consistent with risk loving behavior during the risk elicitation game. Hence, the coefficient estimates imply that a principal who contracts with a pair of agents that have a mean of 6 to 8 Option A choices is likely to increase $W_{2}$ by 1.85 more than if he was contracting with a risk loving pair. And a principal who contracts with a very risk-averse pair that chose an avg of 9 to 15 Option A choices is likely to increase $W_{2}$ by 2.52 more. These results are consistent with theory.

It is again surprising that Dummy 6-8 and Dummy 9-15 have a greater impact on $W_{2}$ than their lags. This suggests that principals are capable of responding to the current risk characteristics of the agents. While this appears to be remarkable, recall that there are only 12 agents per session so the community of agents is fairly small. Thus, each principal may be able to learn session group risk characteristics through observation of performance and acceptance decisions. In order to determine whether such learning is taking place, we reran regression (2) using only the period 1-10 data (regression 3) and then using only the 11-20 period data (regression 4). If our principals are learning about agents' risk preferences, then we ought to observe a difference in the way $W_{2}$ responds to 
the risk dummies across regressions (3) and (4). Indeed, we do see evidence of learning. In regression (3), the coefficients for the risk dummies have mixed signs and none are significant. But in regression (4) the contemporary risk dummies are large, positive and significant at the $1 \%$ level. These results are very intuitive and consistent with theory.

With regard to SP, it is interesting to note that the Prosocial coefficient is not significant but the Envy coefficient is large and significant. If indeed $W_{2}$ is used for incentives, then it is not surprising that an envy type principal will want to provide strong incentives. Note that our interpretation would be different if our default model is the separable utility model where the loser's prize has no incentive effect. In that case, it serves only a distributional role and we would expect an envy type principal to want to reduce $W_{2}$ to gain a greater share of the surplus.

We now turn to Corollary 1(b) which suggests that it is theoretically plausible for $W_{1}$ to decrease in agent's risk aversion, but the conditions are stringent. Consequently, the non-separable model does not provide a clear testable prediction of how $W_{1}$ is affected by risk aversion. This also implies that there is no clear prediction about how the principal adjusts the prize spread in response to a change in risk aversion. This relationship is therefore an empirical question.

Table 10 on the next page reports seven regressions designed to test how $W_{1}$ and $W_{1}-W_{2}$ respond to risk aversion. Regressions (1)-(4) are identical to the regressions in Table 9 with the exception that the dependent variable is now $W_{1}$. Regressions (5)-(7) are also identical with the exception that the dependent variable is $W_{1}-W_{2}$. Focusing first on regressions (1)-(4), we see that most of the risk variables have no significant impact on $W_{1}$. The only sign of significance is the Dummy 6-8 coefficient in regression (3). However, this regression is estimated only on the 1-10 period data and the same coefficient becomes insignificant in regression (4) using the period 11-20 data. Thus, if there is any impact of agent risk on $W_{1}$, it is likely an anomaly made by inexperienced subjects. As an empirical matter, it doesn't appear that $W_{1}$ responds to risk aversion.

The SP variables Prosocial and Envy both have statistically significant impacts on $W_{1}$ but the coefficients have opposite signs. Envy type principals are likely to choose a 
higher $W_{1}$, whereas prosocial types choose lower $W_{1}$. It appears that prosocial types reduce $W_{1}$ which weakens incentives but also reduces inequality. Envy types raise $W_{1}$ to create stronger incentives.

Table 10: Censored Regressions for $W_{1}$ and Spread $W_{1}-W_{2}$ by Principal

\begin{tabular}{|c|c|c|c|c|c|c|c|}
\hline & (1) & (2) & (3) & (4) & (5) & (6) & (7) \\
\hline Dependent Variable & $\begin{array}{c}W_{1} \\
\text { All } \\
\text { Periods }\end{array}$ & $\begin{array}{c}W_{1} \\
\text { All } \\
\text { Periods }\end{array}$ & $\begin{array}{c}W_{1} \\
\text { Periods } \\
1-10\end{array}$ & $\begin{array}{c}W_{1} \\
\text { Periods } \\
11-20\end{array}$ & $\begin{array}{c}W_{1}-W_{2} \\
\text { All } \\
\text { Periods }\end{array}$ & $\begin{array}{c}W_{1}-W_{2} \\
\text { Periods } \\
1-10\end{array}$ & $\begin{array}{c}W_{1}-W_{2} \\
\text { Periods } \\
11-20\end{array}$ \\
\hline Constant & $\begin{array}{c}60.10^{* * *} \\
(10.51)\end{array}$ & $\begin{array}{c}61.47^{* * *} \\
(7.58)\end{array}$ & $\begin{array}{c}65.54 * * * \\
(10.71)\end{array}$ & $\begin{array}{c}88.38 * * * \\
(22.58)\end{array}$ & $\begin{array}{c}42.98^{* * *} \\
(14.12)\end{array}$ & $\begin{array}{l}40.51^{* *} \\
(15.80)\end{array}$ & $\begin{array}{c}63.69^{* * *} \\
(19.15)\end{array}$ \\
\hline Principal Risk & $\begin{array}{c}0.16 \\
(0.85)\end{array}$ & $\begin{array}{c}0.16 \\
(0.82)\end{array}$ & $\begin{array}{c}0.05 \\
(0.82)\end{array}$ & $\begin{array}{c}0.18 \\
(1.06)\end{array}$ & $\begin{array}{c}0.73 \\
(1.21)\end{array}$ & $\begin{array}{c}1.33 \\
(1.11)\end{array}$ & $\begin{array}{c}0.22 \\
(1.42)\end{array}$ \\
\hline Avg Agent Risk & $\begin{array}{l}-0.04 \\
(0.70)\end{array}$ & -- & -- & -- & -- & -- & -- \\
\hline Lag Avg Agent Risk & $\begin{array}{c}0.41 \\
(0.56)\end{array}$ & -- & -- & -- & -- & -- & -- \\
\hline $\begin{array}{l}\text { Dummy 6-8 } \\
\text { (1 if Avg Agent Risk between 6-8) }\end{array}$ & -- & $\begin{array}{l}-1.56 \\
(3.01)\end{array}$ & $\begin{array}{l}-3.16^{* *} \\
(1.51)\end{array}$ & $\begin{array}{l}-1.01 \\
(4.92)\end{array}$ & $\begin{array}{l}-3.14 \\
(3.86)\end{array}$ & $\begin{array}{l}-2.79 \\
(2.09)\end{array}$ & $\begin{array}{l}-4.92 \\
(5.28)\end{array}$ \\
\hline $\begin{array}{l}\text { Dummy 9-15 } \\
\text { (1 if Avg Agent Risk between 9-15) }\end{array}$ & -- & $\begin{array}{l}-0.66 \\
(1.11)\end{array}$ & $\begin{array}{c}0.82 \\
(2.80)\end{array}$ & $\begin{array}{l}-3.00 \\
(2.10)\end{array}$ & $\begin{array}{l}-3.18^{*} \\
(1.82)\end{array}$ & $\begin{array}{l}-0.01 \\
(3.39)\end{array}$ & $\begin{array}{c}-7.77 * * * \\
(1.54)\end{array}$ \\
\hline Lag Dummy 6-8 & -- & $\begin{array}{l}1.83 \\
(2.55)\end{array}$ & $\begin{array}{l}1.16 \\
(2.76)\end{array}$ & $\begin{array}{c}1.87 \\
(2.13)\end{array}$ & $\begin{array}{c}1.54 \\
(3.10)\end{array}$ & $\begin{array}{l}1.90 \\
(2.92)\end{array}$ & $\begin{array}{c}1.23 \\
(3.17)\end{array}$ \\
\hline Lag Dummy 9-15 & -- & $\begin{array}{c}4.25 * * * \\
(1.25)\end{array}$ & $\begin{array}{c}4.78 * * \\
(2.39)\end{array}$ & $\begin{array}{c}3.18 \\
(3.22)\end{array}$ & $\begin{array}{c}2.76^{* *} \\
(1.24)\end{array}$ & $\begin{array}{l}5.91 * \\
(3.30)\end{array}$ & $\begin{array}{l}-0.41 \\
(2.83)\end{array}$ \\
\hline Lag Tournament Offer Rejected & $\begin{array}{c}0.47 \\
(2.00)\end{array}$ & $\begin{array}{c}0.31 \\
(1.93)\end{array}$ & $\begin{array}{c}2.68 \\
(3.22)\end{array}$ & $\begin{array}{l}-1.68 \\
(1.52)\end{array}$ & $\begin{array}{c}-0.72 \\
(1.51)\end{array}$ & $\begin{array}{l}-3.34 * \\
(1.64)\end{array}$ & $\begin{array}{c}1.24 \\
(2.54)\end{array}$ \\
\hline Lag Avg Output of Agents & $\begin{array}{c}0.25 * * * \\
(0.05)\end{array}$ & $\begin{array}{c}0.25^{* * *} \\
(0.04)\end{array}$ & $\begin{array}{c}0.16^{* * *} \\
(0.06)\end{array}$ & $\begin{array}{c}0.32 * * * \\
(0.06)\end{array}$ & $\begin{array}{c}0.17 * * * \\
(0.04)\end{array}$ & $\begin{array}{c}0.04 \\
(0.08)\end{array}$ & $\begin{array}{c}0.30^{* * *} \\
(0.06)\end{array}$ \\
\hline Prosocial & $\begin{array}{c}-5.42 * * \\
(2.65)\end{array}$ & $\begin{array}{c}-5.51 * * \\
(2.55)\end{array}$ & $\begin{array}{c}-3.34 * * \\
(1.60)\end{array}$ & $\begin{array}{c}-7.21 * * \\
(2.88)\end{array}$ & $\begin{array}{l}-3.37 \\
(3.05)\end{array}$ & $\begin{array}{l}-0.81 \\
(3.47)\end{array}$ & $\begin{array}{c}-5.40 * * \\
(2.76)\end{array}$ \\
\hline Envy & $\begin{array}{c}3.55^{* * *} \\
(1.09)\end{array}$ & $\begin{array}{c}3.82 * * * \\
(0.99)\end{array}$ & $\begin{array}{c}4.00^{* * *} \\
(1.17)\end{array}$ & $\begin{array}{c}4.09 * * * \\
(0.78)\end{array}$ & $\begin{array}{l}-2.22 \\
(1.97)\end{array}$ & $\begin{array}{l}-3.51 \\
(3.68)\end{array}$ & $\begin{array}{l}-0.14 \\
(1.12)\end{array}$ \\
\hline No. Obs. & 456 & 456 & 216 & 240 & 456 & 216 & 240 \\
\hline
\end{tabular}

$*, * *, * * *$ signify that coefficients are significantly different from zero at $10 \%, 5 \%$ and $1 \%$ levels.

Regressions are Tobit regressions with robust standard errors adjusted for clustering on sessions in parentheses. All data is from the Endogenous treatment. The dependent variable is meant to capture the endogenous prize spread chosen by principals. Period and period-square variables were also included by estimated coefficients were omitted from the table to conserve space.

Regressions (5)-(7) examine the impact of risk aversion on the $W_{1}-W_{2}$. Although prize compression due to a lowering of $W_{1}$ appears to be unlikely given the results in regressions (1)-(4), compression can still occur since $W_{2}$ increases in agent risk aversion. Regression (5) shows that the Dummy 9-15 coefficient is negative, but only significant at the $10 \%$ level. When we run separate regressions on the 1-10 and 11-20 period data, we 
see that this same coefficient becomes significant using the 11-20 period data; i.e. the Dummy 9-15 coefficient remains negative and increases in absolute value to 7.77, with pvalue $<0.01$. Thus, it appears that, after gaining experience, principals do weaken the prize spread when they contract with extremely risk-averse agents. Moreover, the impact of Prosocial on prize spread in the same regression is consistent with earlier results that prosocial principals weaken incentives. The Envy variable appears to have little impact on prize spread, but this is not inconsistent with earlier results that show that envy types raise both prizes when agents are risk-averse enough.

Overall, our results offer a compelling support for the non-separable utility tournaments model even after controlling for social preferences. We find $W_{2}$ can play an increasing incentive role as agent risk aversion exceeds certain thresholds and that principals appear to be aware of this as they raise $W_{2}$ when agents are risk-averse enough. Our results also suggest that principals will reduce the prize spread for extremely riskaverse agents. Finally, social preferences appear to also explain tournament prize choices and therefore should not be ignored.

\section{Conclusion}

We reports results from an economic experiment designed to test the qualitative implications of canonical tournament theory. On the positive side, we find robust support for classic incentive effects in that raising the winner's prize induces more effort from agents. On the negative side, our experiment generated some empirical puzzles that seemingly contradict standard tournament theory. Controlling for social preferences does not resolve these puzzles. However, these puzzles can be explained using a tournaments model where we relax the textbook assumption that agents' utility functions are separable. Non-separable utility is not a trivial assumption as it implies that agents' cost/disutility of effort depends on marginal utility. When agents are risk-averse, marginal utility is decreasing in wealth due to concavity of the utility function. Thus, raising wealth through higher prizes reduces marginal utility and hence the marginal cost of effort. Raising the loser's prize has a particularly large impact because the agent's marginal utility is higher at lower wealth levels. This implies that the principal has two 
instruments for incentive provision. First, there is the traditional instrument which is to increase prize spread in order to increase the agent's marginal revenue of effort. Second, the principal can raise the loser's prize which reduces the agent's marginal cost of effort. The literature on incentives primarily focuses on the first instrument, and a widely celebrated prediction is that principals reduce the power of incentives when contracting with more risk averse agents. However, the non-separable model predicts that principals should reduce prize spread only under fairly stringent conditions. Moreover, the nonseparable model yields some additional nuanced predictions about the way risk aversion impacts both agents' response to incentives and principals' design of incentives.

Our experimental data allowed us to test the additional implications of the nonseparable model. First, when holding the winner's prize constant, effort is decreasing in the loser's prize at low levels of agent risk aversion but non-decreasing in the loser's prize if agents are sufficiently risk-averse. Second, when holding the prize spread constant, effort is non-increasing in the loser's prize at low levels of agent risk aversion but increasing in the loser's prize if agents are sufficiently risk-averse. Third, subjects assigned to be principals raise the loser's prizes when agent risk aversion crosses certain threshold. These results are particularly pronounced in later periods when the principals had sufficient time to learn about agents' risk preferences. These results are remarkable in their consistency with the predictions of the non-separable utility model and provide compelling evidence that standard tournaments theory is quite useful providing that a key restrictive assumption is relaxed.

While social preferences are not needed to resolve our empirical puzzles, they nevertheless do have direct effects on outcomes. And remarkably, some of these effects can be turned "on" when agents attribute motives to principals; i.e. both envy and prosocial agents exert higher effort in sessions with live principals, but not in sessions where the computer assigns the tournament prizes. We also find that envy type principals deliver stronger incentives to agents while prosocial principals weaken incentives.

One might naturally ask whether our results are a function of the small stakes used in our experiment. An advantage of the non-separable model is that it can be used 
to generate predictions of what might happen if stakes were raised. Higher average wealth can reduce marginal utility and hence reduce the marginal cost of effort. Thus, raising wealth should have a similar impact as reducing risk aversion. Since our model already yields predictions based on variations in risk aversion, most of the predictions can also apply for variations in wealth.

What we have learned is that tournament models with non-separable utility are very useful models as they yield predictions that are remarkably consistent with empirical regularities of our experimental data. An important lesson from this research is that simple theories based on selfish preferences often fail not because we fail to incorporate more complex or "realistic" behavioral motives, but rather because we fail to scrutinize functional forms on important primitives. Nonetheless, these models can be enriched by adding social preferences. There is a tendency for behavioral and experimental economics to view canonical economic theory with skepticism and see social preference and behavioral models as substitutes (Samuelson 2005; Rubinstein 2006; Levine and Zheng forthcoming). This research suggests that canonical and behavioral models might be more appropriately seen as complements rather than substitutes in improving tournament models in the future. 


\section{REFERENCES}

Agranov, M. and C. Tergiman. 2011. "Incentives and Compensation Schemes: An Experimental Study." Working Paper.

Akerlof, G. 1982. "Labor Contracts as Partial Gift Exchange.” Quarterly Journal of Economics 97 (4): 543-569.

Bartling, B., E. Fehr, M.A. Marechal, and D. Schunk. 2009. "Egalitarianism and Competitiveness." American Economic Review 99 (2): 93-98.

Bolton, G.E., and A. Ockenfels. 2000. "ERC: A Theory of Equity, Reciprocity, and Competition." American Economic Review 90 (1): 166-193.

Bolton, P., and M. Dewatripont. 2005. Contract Theory. Cambridge, M.A.: The MIT Press.

Bull, C., A. Schotter, and K. Weigelt. 1987. "Tournaments and Piece Rates: An Experimental Study." Journal of Political Economy 95 (1): 1-33.

Cason, T., W.A. Masters, and R.M. Sheremeta. 2010. "Entry into Winner-Take-All and Proportional-Prize Contests: An Experimental Study." Journal of Public Economics 94 (9-10): 604-611.

Charness, G. 2004. "Attribution and Reciprocity in an Experimental Labor Market." Journal of Labor Economics 22 (3): 665-688.

Charness, G., and P. Kuhn. 2011. "Lab labor: What can labor economists learn from the lab?" In: Ashenfelter, O., Card, D. (Eds.), Handbook of Labor Economics, vol. 4A. Elsevier, pp. 229-331.

Che, Y.K., and I. Gale. 2000. "Difference-form Contests and the Robustness of All-Pay Auctions." Games and Economic Behavior 30 (1): 22-43.

Eriksson, T., S. Teyssier, and M.C. Villeval. 2009. "Self-Selection And The Efficiency Of Tournaments." Economic Inquiry 47 (3): 530-548.

Falk, A., E. Fehr, and D. Huffman. 2008. "The Power and Limits of Tournament Incentives." Working Paper.

Fehr, E., and K.M. Schmidt. 1999. "A Theory of Fairness, Competition, and Cooperation." The Quarterly Journal of Economics 114 (3): 817-868.

Fehr, E., G. Kirchsteiger, and A. Riedl. 1993. "Does Fairness Prevent Market Clearing? An Experimental Investigation.” Quarterly Journal of Economics 58 (2): 437460.

Fischbacher, U. 2007. "z-Tree: Zurich Toolbox for Ready-Made Economic Experiments." Experimental Economics 10 (2): 171-178.

Freeman, R.B., and A.M. Gelber. 2010. "Prize Structure and Information in Tournaments: Experimental Evidence." American Economic Journal: Applied Economics 2 (1): 149-164.

Green, J.R., and N.L. Stokey. 1983. "A Comparison of Tournament Contracts.” The Journal of Political Economy 91 (3): 349-364.

Grund, C., and D. Sliwka. 2005. "Envy and Compassion in Tournaments." Journal of Economic Management and Strategy 14 (1): 187-207. 
Harbring, C., and B. Irlenbusch. 2005. "Incentives in Tournaments with Endogenous Prize Selection." Journal of Institutional and Theoretical Economics 161 (4): 636-663.

Healy, P.J. 2007. "Group Reputations, Stereotypes, and Cooperation in a Repeated Labor Market." American Economic Review 97 (5): 1751-1773.

Holt, C.A., and S.K. Laury. 2002. "Risk Aversion and Incentive Effects." American Economic Review 92 (5): 1644-1655.

Laffont, J.J., and D. Martimort. 2002. The Theory of Incentives: The Principal-Agent Model. Princeton, N.J.: Princeton University Press.

Levine, D., and J. Zheng. forthcoming. The Relationship of Economic Theory to Experiments. In The Methods of Modern Experimental Economics. eds. G. Frechette and A. Schotter. Oxford University Press.

Nalbantian, H.R., and A. Schotter. 1997. "Productivity under Group Incentives: An Experimental Study." American Economic Review 87 (3): 314-341.

Nieken, P. 2010. "On the Choice of Risk and Effort in Tournaments - Experimental Evidence." Journal of Economic Management and Strategy 19 (3): 811-840.

Orrison, A., A. Schotter, and K. Weigelt. 2004. "Multiperson Tournaments: An Experimental Examination." Management Science 50 (2): 268-279.

Rubinstein, A. 2006. "Dilemmas of an Economic Theorist." Econometrica 74 (4): 865883.

Samuelson, L. 2005. "Economic Theory and Experimental Economics." Journal of Economic Literature 43 (1): 65-107.

Schotter, A., and K. Weigelt. 1992. "Asymmetric Tournaments, Equal Opportunity Laws and Affirmative Action: Some Experimental Results." Quarterly Journal of Economics 107 (2): 511-539.

Tirole, J. 1999. “Incomplete Contracts: Where do We Stand?" Econometrica 67 (4): 741781.

Wu, S., and B. Roe. 2005. "Behavioral and Welfare Effects of Tournaments versus Fixed Performance Contracts: Some Experimental Evidence." American Journal of Agricultural Economics 87 (1): 130-146. 


\section{FOR ONLINE PUBLICATION}

\section{Appendix A: Proofs of Propositions and Corollaries}

Note: For equations that appear both in the main article and Appendix, the original equation numbers from the article are retained. Equations that are in the Appendix but not in the main article are assigned a number proceeding with an "A". For example, equation (A1). The same holds for Propositions, Remarks, and Corollaries.

Proposition 1: A risk-neutral agent optimally responds to a change in tournament prize structure as follows:

a) Effort increases with an increase in $W_{1}$ holding $W_{2}$ constant (prize spread increases);

b) Effort decreases in $W_{2}$ holding $W_{1}$ constant (prize spread decreases);

c) Effort does not change with a change in $W_{2}$ holding prize spread $\left(W_{1}-W_{2}\right)$ constant;

d) An increase in either the prize spread or $W_{2}$ (holding the other constant) relaxes agents' participation constraint and induces more participation.

Proof: We begin by showing parts (a) through (c). Suppose that a risk-neutral agent $i$ competes against another agent $j$ in a two player tournament where the winner receives $W_{1}$ and the loser receives $W_{2}$. In this simultaneous move game, agent $i$ 's best response is given by,

$$
\frac{\partial E\left(\pi_{i}^{A}\right)}{\partial e_{i}}=\frac{\partial p_{i}}{\partial e_{i}}\left(W_{1}-W_{2}\right)=\frac{d c\left(e_{i}\right)}{d e_{i}} .
$$

Totally differentiating (2) with respect to $e_{i}, W_{1}$ and $W_{2}$ and using the more compact notation $p_{e}=\frac{\partial p_{i}}{\partial e_{i}}$ for partial derivative and $c^{\prime}(e)=\frac{d c\left(e_{i}\right)}{d e_{i}}$, where the subscript $i$ is suppressed since we are focusing on a symmetric equilibrium, yields (A1) $\quad\left\{p_{e e}\left[W_{1}-W_{2}\right]-c^{\prime \prime}(e)\right\} d e+p_{e} d W_{1}-p_{e} d W_{2}=0$.

To show part (a), set $d W_{2}=0$ and rearranging (A1) yields the result

$$
\left.\frac{d e}{d W_{1}}\right|_{d W_{2}=0}=\frac{-p_{e}}{p_{e e}\left[W_{1}-W_{2}\right]-c^{\prime \prime}(e)} .
$$

Since the agent's objective function must be sufficiently concave to guarantee a symmetric equilibrium, the denominator of (A2) must be negative. Hence, it follows that (A2) is positive so that effort is increasing in $W_{1}$. This proves part (a).

To show part (b), set $d W_{1}=0$ and rearrange (A1) to get 
(A3) $\left.\frac{d e}{d W_{2}}\right|_{d W_{1}=0}=\frac{p_{e}}{p_{e e}\left[W_{1}-W_{2}\right]-c^{\prime \prime}(e)}$.

(A3) is clearly negative which proves part (b).

To show part (c), if we are holding the spread constant, then we must let $d W_{1}>0$ when $d W_{2}$ changes such that $\frac{d W_{1}}{d W_{2}}=1$. Rearranging (A1) yields

(A4) $\frac{d e}{d W_{1}}=\frac{-p_{e} \frac{d W_{1}}{d W_{2}}+p_{e}}{p_{e e}\left[W_{1}-W_{2}\right]-c^{\prime \prime}(e)}=\frac{-p_{e}(1)+p_{e}}{p_{e e}\left[W_{1}-W_{2}\right]-c^{\prime \prime}(e)}=0$.

Hence, increasing $W_{2}$ while holding spread constant should have no impact on effort.

To prove part (d), we can use the envelope theorem to the objective function (1) to show that,

(A5) $\frac{d E\left(\pi_{i}^{A}\right)}{d W_{1}}=p>0$

$$
\frac{d E\left(\pi_{i}^{A}\right)}{d W_{2}}=1-p>0
$$

which proves (d).

Proposition 2: Suppose that an agent's expected utility is such that $E\left[U\left(\pi_{i}^{A}\right)\right]=p_{i} u\left(W_{1}\right)+\left(1-p_{i}\right) u\left(W_{2}\right)-c\left(e_{i}\right)$ where $u^{\prime}(\bullet)>0$ and $u^{\prime \prime}(\bullet)<0$. Then:

a) Effort increases with an increase in $W_{1}$ holding $W_{2}$ constant;

b) Effort decreases in $W_{2}$ holding $W_{1}$ constant;

c) Effort is decreasing in $W_{2}$ holding prize spread $\left(W_{1}-W_{2}\right)$ constant;

d) An increase in either the prize spread or $W_{2}$ (holding the other constant) relaxes agents' participation constraint and induces more participation.

Proof: We begin by showing parts (a) through (c). Suppose that a risk-averse agent $i$ competes against another agent $j$ in a two player tournament where the winner receives $W_{1}$ and the loser receives $W_{2}$. In this simultaneous move game, agent $i$ 's best response is given by,

$$
\frac{\partial E\left[u\left(\pi_{i}^{A}\right)\right]}{\partial e_{i}}=\frac{\partial p_{i}}{\partial e_{i}}\left[u\left(W_{1}\right)-u\left(W_{2}\right)\right]=\frac{d c\left(e_{i}\right)}{d e_{i}} .
$$


Totally differentiating (A7) with respect to $e_{i}, W_{1}$ and $W_{2}$ and using the more compact notation $p_{e}=\frac{\partial p_{i}}{\partial e_{i}}$ for partial derivative and $c^{\prime}(e)=\frac{d c\left(e_{i}\right)}{d e_{i}}$ where the subscript $i$ is suppressed since we are focusing on a symmetric equilibrium, yields

$$
\left\{p_{e e}\left[u\left(W_{1}\right)-u\left(W_{2}\right)\right]-c^{\prime \prime}(e)\right\} d e+p_{e} u^{\prime}\left(W_{1}\right) d W_{1}-p_{e} u^{\prime}\left(W_{2}\right) d W_{2}=0 .
$$

To show part (a), set $d W_{2}=0$ and rearranging (A8) yields the result

$$
\left.\frac{d e}{d W_{1}}\right|_{d W_{2}=0}=\frac{-p_{e} u^{\prime}\left(W_{1}\right)}{p_{e e}\left[u\left(W_{1}\right)-u\left(W_{2}\right)\right]-c^{\prime \prime}(e)} .
$$

Since the agent's utility function must be sufficiently concave to guarantee a symmetric equilibrium, the denominator of (A9) must be negative. Moreover the numerator must be negative. Hence, it follows that (A9) is positive so that effort is increasing in $W_{1}$. This proves part (a).

To show part (b), set $d W_{1}=0$ and rearranging (A8) yields the result

(A10) $\left.\frac{d e}{d W_{2}}\right|_{d W_{1}=0}=\frac{p_{e} u^{\prime}\left(W_{1}\right)}{p_{e e}\left[u\left(W_{1}\right)-u\left(W_{2}\right)\right]-c^{\prime \prime}(e)}$.

It is obvious that (A10) must be negative, which proves (b).

To show part (c), if we are holding the spread constant, then we must let $d W_{1}>0$ when $d W_{2}>0$ such that $\frac{d W_{1}}{d W_{2}}=1$. Rearranging (A8) yields

(A11) $\frac{d e}{d W_{2}}=\frac{p_{e} u^{\prime}\left(W_{2}\right)-p_{e} u^{\prime}\left(W_{1}\right) \frac{d W_{1}}{d W_{2}}}{p_{e e}\left[u\left(W_{1}\right)-u\left(W_{2}\right)\right]-c^{\prime \prime}(e)}=\frac{p_{e}\left[u^{\prime}\left(W_{2}\right)-u^{\prime}\left(W_{1}\right)\right](1)}{p_{e e}\left[u\left(W_{1}\right)-u\left(W_{2}\right)\right]-c^{\prime \prime}(e)}$.

Given the strict concavity of the utility function, it follows that $u^{\prime}\left(W_{2}\right)>u^{\prime}\left(W_{1}\right)$ so that the numerator is positive. This combined with the negative denominator implies that (A11) is negative which proves part (c).

To prove part (d), we can use the envelope theorem to show that,

$$
\begin{aligned}
& \text { (A12) } \frac{d E\left(\pi_{i}^{A}\right)}{d W_{1}}=p u^{\prime}\left(W_{1}\right)>0, \\
& \text { (A13) } \frac{d E\left(\pi_{i}^{A}\right)}{d W_{2}}=(1-p) u^{\prime}\left(W_{2}\right)>0,
\end{aligned}
$$

which proves (d).

Proposition 3: The solution to (4) yields and optimal tournament structure: 

a) $\quad W_{2}^{*}=v+c\left[e^{*}\left(W_{1}^{*}, W_{2}^{*}\right)\right]-\frac{c^{\prime}\left[e^{*}\left(W_{1}^{*}, W_{2}^{*}\right)\right]}{2 p_{e}}$;
b) $\quad W_{1}^{*}=v+c\left[e^{*}\left(W_{1}^{*}, W_{2}^{*}\right)\right]+\frac{c^{\prime}\left[e^{*}\left(W_{1}^{*}, W_{2}^{*}\right)\right]}{2 p_{e}}$;
c) $\quad 1=c^{\prime}\left[e^{*}\left(W_{1}^{*}, W_{2}^{*}\right)\right]$.

Proof: To show that (a)-(c) is the solution to (4), first we can assume that a profit maximizing principal will not leave the agent with rents. Therefore, solving for the participation constraint and substituting into the objective function yields

(A14) $\max _{W_{1}, W_{2}} 2\left[e^{*}\left(W_{2}, W_{2}\right)-v-c\left[e^{*}\left(W_{2}, W_{2}\right)\right]\right]$.

The first order conditions are

$$
\begin{aligned}
& 2\left[\frac{\partial e^{*}}{\partial W_{1}}-c^{\prime}(\bullet) \frac{\partial e^{*}}{\partial W_{1}}\right]=0, \\
& 2\left[\frac{\partial e^{*}}{\partial W_{2}}-c^{\prime}(\bullet) \frac{\partial e^{*}}{\partial W_{2}}\right]=0 .
\end{aligned}
$$

It is straightforward to see that both (A15) and (A16) imply that $1=c^{\prime}\left[e^{*}\left(W_{1}^{*}, W_{2}^{*}\right)\right]$ so that the contract calls for the first best level of effort. This proves part (c).

Given the optimal effort level specified by (c), one can easily solve for the optimal (cost minimizing) tournament prizes. The least cost tournament prizes just satisfy binding participation and incentive compatibility constraints. That is, letting $e^{*}=e^{*}\left(W_{1}^{*}, W_{2}^{*}\right)$ and solving
(A17)$$
p_{e}\left[W_{1}-W_{2}\right]-c^{\prime}\left(e^{*}\right)=0
$$
(A18) $W_{2}+\frac{1}{2}\left[W_{1}-W_{2}\right]-c\left(e^{*}\right)=v$,

for $W_{1}$ and $W_{2}$ yields the solutions outlined in parts (a) and (b).

Proposition 4: The optimal tournament when agents have expected utility such that $E\left[u\left(\pi_{i}^{A}\right)\right]=p_{i} u\left(W_{1}\right)+\left(1-p_{i}\right) u\left(W_{2}\right)-c\left(e_{i}\right)$, where $u^{\prime}(\bullet)>0$ and $u^{\prime \prime}(\bullet)<0$, is:

a)

$$
\begin{aligned}
& W_{2}^{*}=u^{-1}\left[v+c\left[e^{*}\left(W_{1}^{*}, W_{2}^{*}\right)\right]-\frac{c^{\prime}\left[e^{*}\left(W_{1}^{*}, W_{2}^{*}\right)\right]}{2 p_{e}}\right] ; \\
& W_{1}^{*}=u^{-1}\left[v+c\left[e^{*}\left(W_{1}^{*}, W_{2}^{*}\right)\right]+\frac{c^{\prime}\left[e^{*}\left(W_{1}^{*}, W_{2}^{*}\right)\right]}{2 p_{e}}\right] ;
\end{aligned}
$$

b) 
c) $\quad e^{*}\left(W_{1}^{*}, W_{2}^{*}\right) \in \underset{e}{\arg \max } 2\left\{e-\frac{1}{2}\left(u^{-1}\left[v+c[e]+\frac{c^{\prime}[e]}{2 p_{e}}\right]+u^{-1}\left[v+c[e]-\frac{c^{\prime}[e]}{2 p_{e}}\right]\right)\right\}$.

Proof: To show that (a) through (c) is the optimal contract, we do not take the approach we did for Proposition 2 because this is a less tractable problem due to risk aversion. Instead, we set up the principal's contract design problem is

Letting $\mu$ and $\lambda$ denote the lagrange multipliers for the incentive compatibility and participation constraints, respectively, the first order conditions (after rearranging slightly) are
(A20) $\frac{2 p_{i}}{u^{\prime}\left(W_{1}\right)}=\lambda p_{i}+\mu p_{i e}$,
(A21) $\frac{2 p_{i}}{u^{\prime}\left(W_{2}\right)}=\lambda\left(1-p_{i}\right)-\mu p_{i e}$,
(A22) $u\left(W_{2}\right)+p_{i}\left[u\left(W_{1}\right)-u\left(W_{2}\right)\right]-c\left(e^{*}\right) \geq v$,
(A23) $p_{e}\left[u\left(W_{1}\right)-u\left(W_{2}\right)\right]-c^{\prime}\left(e^{*}\right) \geq 0$.

Adding (A20) and (A21) together yields

(A24) $\lambda=\frac{2 p_{i}}{u^{\prime}\left(W_{1}\right)}+\frac{2 p_{i}}{u^{\prime}\left(W_{2}\right)}>0$.

Hence, the agent's participation constraint must bind. Substituting (A24) into (A20) yields

$$
\mu=\frac{2 p_{i}}{p_{i e}}\left[\frac{1-p_{i}}{u^{\prime}\left(W_{1}\right)}-\frac{p_{i}}{u^{\prime}\left(W_{2}\right)}\right]
$$

In a symmetric equilibrium, $1-p_{i}=p_{i}=\frac{1}{2}$, and since $u^{\prime}\left(W_{1}\right)<u^{\prime}\left(W_{2}\right)$, it follows that (A25) is positive and the incentive compatibility constraint must also bind. Since both the participation (A22) and incentive compatibility (A23) constraints must hold with equality, we can solve for the optimal prizes as we have two equation and two unknowns.

The solutions are

$$
\begin{aligned}
& W_{1}^{*}=u^{-1}\left[v+c\left[e^{*}\left(W_{1}^{*}, W_{2}^{*}\right)\right]+\frac{c^{\prime}\left[e^{*}\left(W_{1}^{*}, W_{2}^{*}\right)\right]}{2 p_{e}}\right], \\
& W_{2}^{*}=u^{-1}\left[v+c\left[e^{*}\left(W_{1}^{*}, W_{2}^{*}\right)\right]-\frac{c^{\prime}\left[e^{*}\left(W_{1}^{*}, W_{2}^{*}\right)\right]}{2 p_{e}}\right],
\end{aligned}
$$


which proves parts (a) and (b).

Part (c) follows naturally since plugging (A26) and (A27) into the principal's objective function yields

$$
2\left\{e-\frac{1}{2}\left(u^{-1}\left[v+c[e]+\frac{c^{\prime}[e]}{2 p_{e}}\right]+u^{-1}\left[v+c[e]-\frac{c^{\prime}[e]}{2 p_{e}}\right]\right)\right\}
$$

Hence, the optimal effort must maximize (A25) or

$$
e^{*}\left(W_{1}^{*}, W_{2}^{*}\right) \in \underset{e}{\arg \max } 2\left\{e-\frac{1}{2}\left(u^{-1}\left[v+c[e]+\frac{c^{\prime}[e]}{2 p_{e}}\right]+u^{-1}\left[v+c[e]-\frac{c^{\prime}[e]}{2 p_{e}}\right]\right)\right\} .
$$

Proposition 5: A risk-averse agent with non-separable utility optimally responds to a change in tournament prize structure as follows:

a) Effort increases with an increase in $W_{1}$ holding $W_{2}$ constant;

b) If the agent's coefficient of absolute risk aversion $r_{A}\left(W_{2}-c(e)\right) \geq \frac{p_{e}}{c^{\prime}(e)\left(1-p_{i}\right)}$ then effort is non-decreasing in $W_{2}$ holding $W_{1}$ constant;

c) If $r_{A}\left(W_{2}-c(e)\right) \geq \frac{p_{e}}{c^{\prime}(e)\left(1-p_{i}\right)}-\frac{u^{\prime}\left[W_{1}-c(e)\right]}{u^{\prime}\left[W_{2}-c(e)\right]} \frac{\left[p_{e}+p r_{A}\left(W_{1}-c(e)\right) c^{\prime}(e)\right]}{(1-p) c^{\prime}(e)}$, then effort is increasing in $W_{2}$ holding the prize spread constant;

d) An increase in either $W_{1}$ or $W_{2}$ (holding the other constant) relaxes agents' participation constraint and induces more participation.

Proof: We begin by showing parts (a) and (b). Suppose that a risk-averse agent $i$ with non-separable utility competes against another agent $j$ in a two player tournament where the winner receives $W_{1}$ and the loser receives $W_{2}$. In this simultaneous move game, agent $i$ 's best response is given by (6). Totally differentiating (6) with respect to $e_{i}, W_{1}$ and $W_{2}$, using more compact notation and focusing on a symmetric equilibrium yields

$$
\begin{aligned}
& \{S O C\} d e+\left\{p_{e} u^{\prime}\left[W_{1}-c(e)\right]-p u^{\prime \prime}\left[W_{1}-c(e)\right] c^{\prime}(e)\right\} d W_{1} \\
& \quad+\left\{-p_{e} u^{\prime}\left[W_{2}-c(e)\right]-(1-p) u^{\prime \prime}\left[W_{2}-c(e)\right] c^{\prime}(e)\right\} d W_{2}=0
\end{aligned}
$$

where SOC is the second derivative of the agent's expected utility (5) with respect to $e$, which must be negative in order for the agent's objective function to be concave. To show part (a), set $d W_{2}=0$ and let $r_{A}\left(W_{1}-c(e)\right)=-\frac{u^{\prime \prime}\left[W_{1}-c(e)\right]}{u^{\prime}\left[W_{1}-c(e)\right]}$. Then rearranging (A30) yields the result

(A31) $\left.\frac{d e}{d W_{1}}\right|_{d W_{2}=0}=\frac{-u^{\prime}\left[W_{1}-c(e)\right]\left[p_{e}+r_{A}\left(W_{1}-c(e)\right) p c^{\prime}(e)\right]}{S O C}$. 
Since the agent's utility function must be sufficiently concave to guarantee a symmetric equilibrium, the denominator, SOC must be negative. Therefore, effort increases in $W_{1}$.

To show part (b), set $d W_{1}=0$ and let $r_{A}\left(W_{2}-c(e)\right)=-\frac{u^{\prime \prime}\left[W_{2}-c(e)\right]}{u^{\prime}\left[W_{2}-c(e)\right]}$. Rearranging (A30) yields

(A32) $\left.\frac{d e}{d W_{2}}\right|_{d W_{1}=0}=\frac{u^{\prime}\left[W_{2}-c(e)\right]\left[p_{e}-r_{A}\left(W_{2}-c(e)\right)(1-p) c^{\prime}(e)\right]}{S O C}$.

Note that (A32) is non-negative if $p_{e}-r_{A}\left(W_{2}-c(e)\right)(1-p) c^{\prime}(e) \leq 0$ which is equivalent to $r_{A}\left[W_{2}-c(e)\right] \geq \frac{p_{e}}{(1-p) c^{\prime}(e)}$. Hence, effort is non-decreasing in $W_{2}$ if $r_{A}\left[W_{2}-c(e)\right] \geq \frac{p_{e}}{(1-p) c^{\prime}(e)}$

To show part (c), if we are holding the spread constant, then we must let $d W_{1}>0$ when $d W_{2}>0$ such that $\frac{d W_{1}}{d W_{2}}=1$. Rearranging (A30) yields

(A33)

$$
\begin{aligned}
& \frac{d e}{d W_{2}}=\frac{-u^{\prime}\left[W_{1}-c(e)\right]\left[p_{e}+r_{A}\left(W_{1}-c(e)\right) p c^{\prime}(e)\right] \frac{d W_{1}}{d W_{2}}+u^{\prime}\left[W_{2}-c(e)\right]\left[p_{e}-r_{A}\left(W_{2}-c(e)\right)(1-p) c^{\prime}(e)\right]}{S O C} \\
& =\frac{-u^{\prime}\left[W_{1}-c(e)\right]\left[p_{e}+r_{A}\left(W_{1}-c(e)\right) p c^{\prime}(e)\right](1)+u^{\prime}\left[W_{2}-c(e)\right]\left[p_{e}-r_{A}\left(W_{2}-c(e)\right)(1-p) c^{\prime}(e)\right]}{S O C}
\end{aligned}
$$

If the numerator of (A33) is negative, then (A33) is positive since the denominator is negative. It is easy to verify that the numerator satisfying $-u^{\prime}\left[W_{1}-c(e)\right]\left[p_{e}+r_{A}\left(W_{1}-c(e)\right) p c^{\prime}(e)\right](1)+u^{\prime}\left[W_{2}-c(e)\right]\left[p_{e}-r_{A}\left(W_{2}-c(e)\right)(1-p) c^{\prime}(e)\right]<0$ is equivalent to $r_{A}\left(W_{2}-c(e)\right) \geq \frac{p_{e}}{c^{\prime}(e)\left(1-p_{i}\right)}-\frac{u^{\prime}\left[W_{1}-c(e)\right]}{u^{\prime}\left[W_{2}-c(e)\right]} \frac{\left[p_{e}+p r_{A}\left(W_{1}-c(e)\right) c^{\prime}(e)\right]}{(1-p) c^{\prime}(e)}$. Therefore, so long as $r_{A}\left(W_{2}-c(e)\right) \geq \frac{p_{e}}{c^{\prime}(e)\left(1-p_{i}\right)}-\frac{u^{\prime}\left[W_{1}-c(e)\right]}{u^{\prime}\left[W_{2}-c(e)\right]} \frac{\left[p_{e}+p r_{A}\left(W_{1}-c(e)\right) c^{\prime}(e)\right]}{(1-p) c^{\prime}(e)}$ , then effort is increasing in $W_{2}$ holding the prize spread constant.

To prove part (d), we can apply the envelope theorem to show that (A34) $\frac{d E\left(\pi_{i}^{A}\right)}{d W_{1}}=p u^{\prime}\left[W_{1}-c(e)\right]>0$, 
(A35) $\frac{d E\left(\pi_{i}^{A}\right)}{d W_{2}}=(1-p) u^{\prime}\left[W_{1}-c(e)\right]>0$,

which proves part (d).

Proposition 6: When agents have non-separable utility and if the coefficient of absolute risk aversion is large enough, then under the optimal contract,

a) the participation constraint is not binding and the agent earns rents; and

b) even if the agent's participation constraint is not binding, the incentive compatibility constraint is still binding.

Proof: To show part (a), add-up first order conditions (9) and (10) and solve for $\lambda$ to get (A36)

$$
\lambda=\left[\frac{2 p_{i}}{u^{\prime}\left[W_{1}-c\left(e_{i}\right)\right]}+\frac{2 p_{i}}{u^{\prime}\left[W_{2}-c\left(e_{i}\right)\right]}\right]-\mu c^{\prime}\left(e_{i}\right)\left[p_{i} r_{A}\left(W_{1}-c\left(e_{i}\right)\right)+\left(1-p_{i}\right) r_{A}\left(W_{2}-c\left(e_{i}\right)\right)\right] .
$$

Note that if (A36) is positive, then the participation constraint is binding. This can only happen if $p_{i} r_{A}\left(W_{1}-c\left(e_{i}\right)\right)+\left(1-p_{i}\right) r_{A}\left(W_{2}-c\left(e_{i}\right)\right)$ is sufficiently small. If the coefficients of absolute risk aversion $r_{A}\left(W_{1}-c\left(e_{i}\right)\right)$ and $r_{A}\left(W_{1}-c\left(e_{i}\right)\right)$ are large enough so that $\mu c^{\prime}\left(e_{i}\right)\left[p_{i} r_{A}\left(W_{1}-c\left(e_{i}\right)\right)+\left(1-p_{i}\right) r_{A}\left(W_{2}-c\left(e_{i}\right)\right)\right] \geq \frac{2 p_{i}}{u^{\prime}\left[W_{1}-c\left(e_{i}\right)\right]}+\frac{2 p_{i}}{u^{\prime}\left[W_{2}-c\left(e_{i}\right)\right]}$, then the participation constraint will not bind.

To show part(b), assume that part(a) holds so that the agent's participation constraint does not bind. Letting $\lambda=0$ and solving (A36) for $\mu$ yields

$$
\mu=\frac{\left[\frac{2 p_{i}}{u^{\prime}\left[W_{1}-c\left(e_{i}\right)\right]}+\frac{2 p_{i}}{u^{\prime}\left[W_{2}-c\left(e_{i}\right)\right]}\right]}{c^{\prime}\left(e_{i}\right)\left[p_{i} r_{A}\left(W_{1}-c\left(e_{i}\right)\right)+\left(1-p_{i}\right) r_{A}\left(W_{2}-c\left(e_{i}\right)\right)\right]} .
$$

It is obvious that the right hand side of $\mathrm{A}(37)$ is strictly positive so $\mu>0$ and the incentive compatibility constraint must be binding.

Corollary 1: Suppose that the agent's participation constraint does not bind and that the necessary and sufficient conditions for the principal's profit maximizing tournament design problem are satisfied. Then the following describes how a change in the coefficient of absolute risk aversion affects the principal's prizes choices:

a) $\quad W_{2}$ increases with a marginal increase in the agent's coefficient of absolute riskaverse (across all income levels) if and only if

$$
r_{A}\left[W_{2}-c(e)\right]-r_{A}\left[W_{1}-c(e)\right]<\frac{p_{e}}{p(1-p) c^{\prime}(e)}
$$


b) $\quad W_{1}$ decreases with a marginal increase in the agent's coefficient of absolute risk aversion (across all income levels) if and only if either (i) $r_{A}\left[W_{2}-c(e)\right]>\frac{p_{e}}{(1-p) c^{\prime}(e)}$

$$
\begin{aligned}
& \text { and } r_{A}\left[W_{2}-c(e)\right]-r_{A}\left[W_{1}-c(e)\right]<\frac{p_{e}}{p(1-p) c^{\prime}(e)} \text {, or (ii) } r_{A}\left[W_{2}-c(e)\right]<\frac{p_{e}}{(1-p) c^{\prime}(e)} \text { and } \\
& r_{A}\left[W_{2}-c(e)\right]-r_{A}\left[W_{1}-c(e)\right]>\frac{p_{e}}{p(1-p) c^{\prime}(e)} \text {. }
\end{aligned}
$$

Proof: We restrict attention to a symmetric equilibrium. Assume that Proposition 5 holds so that the participation constraint is not binding. We also know from Proposition 5 that the incentive compatibility constraint is binding. Then the active first order necessary conditions in the principal's contract design problem are (9), (10) and (12). Totally differentiating these first order conditions with respect to $W_{1}, W_{2}, \mu$, and $r_{A}$ (note: we are letting $r_{A}$ to change independent of the wealth level. If we had totally differentiated with respect to $r_{A}\left[W_{k}-c(e)\right]$ where $k=1,2$, then this implies that risk aversion would change at a specific income level only) yields:

(A38) $A_{11} d W_{1}+A_{13} d \mu=-B_{1} d r_{A}$,

(A39) $A_{22} d W_{2}+A_{23} d \mu=-B_{2} d r_{A}$,

(A40) $A_{31} d W_{1}+A_{32} d W_{2}=0$,

where

(A41)

$A_{11}=u^{\prime \prime}\left[W_{1}-c(e)\right] \mu\left[p_{e}+p r_{A}\left(W_{1}-c(e)\right) c^{\prime}(e)\right]+u^{\prime}\left[W_{1}-c(e)\right] \mu p r_{A}^{\prime}\left(W_{1}-c(e)\right) c^{\prime}(e)$,

$$
A_{13}=u^{\prime}\left[W_{1}-c(e)\right]\left[p_{e}+p r_{A}\left(W_{1}-c(e)\right) c^{\prime}(e)\right]
$$

$A_{22}=u^{\prime \prime}\left[W_{2}-c(e)\right] \mu\left[-p_{e}+(1-p) r_{A}\left(W_{2}-c(e)\right) c^{\prime}(e)\right]+u^{\prime}\left[W_{2}-c(e)\right] \mu(1-p) r_{A}^{\prime}\left(W_{2}-c(e)\right) c^{\prime}(e)$

(A44) $A_{23}=u^{\prime}\left[W_{2}-c(e)\right]\left[-p_{e}+(1-p) r_{A}\left(W_{2}-c(e)\right) c^{\prime}(e)\right]$,

(A45) $A_{31}=p_{e} u^{\prime}\left[W_{1}-c(e)\right]-p u^{\prime \prime}\left(W_{1}-c(e)\right) c^{\prime}(e)$,

$$
A_{32}=u^{\prime}\left[W_{2}-c(e)\right]\left[-p_{e}+(1-p) r_{A}\left(W_{2}-c(e)\right) c^{\prime}(e)\right]
$$

(A47) $B_{1}=u^{\prime}\left[W_{1}-c(e)\right] \mu p c^{\prime}(e)$,

(A48) $B_{2}=u^{\prime}\left[W_{2}-c(e)\right] \mu(1-p) c^{\prime}(e)$.

Our goal is to apply Cramer's rule to the system (A38)-(A40) to solve for $\frac{d W_{1}}{d r_{A}}$ and $\frac{d W_{1}}{d r_{A}}$.

First, the determinant of (A38)-(A40) is given by 
(A49) $|D|=\left|\begin{array}{ccc}A_{11} & 0 & A_{13} \\ 0 & A_{22} & A_{23} \\ A_{31} & A_{32} & 0\end{array}\right|=-A_{11} A_{23} A_{32}-A_{13} A_{22} A_{31}$.

A sufficient condition for profit maximization is for (A49) to be positive as this satisfies the second order conditions. (Note: this is not a stringent assumption. It is

straightforward to see that $A_{11}<0$ since $u^{\prime \prime}\left[W_{1}-c(e)\right]<0$ and $r_{A}^{\prime}\left(W_{1}-c(e)\right) \leq 0$ by assumption. It is also obvious that both $A_{13}$ and $A_{31}$ are positive. Moreover, $A_{32}$ and $A_{23}$ are identical so their product is always positive. Finally, a sufficient (but not necessary) condition for $A_{22} \leq 0$ is $-p_{e}+(1-p) r_{A}\left(W_{2}-c(e)\right) c^{\prime}(e)>0$, which is equivalent to $r_{A}\left(W_{2}-c(e)\right)>\frac{p_{e}}{(1-p) c^{\prime}(e)}$, a condition we have already used in Proposition 4).

To show that $W_{2}$ can be increasing in the agent's coefficient of absolute risk aversion, we will use Cramer's rule to solve for $\frac{d W_{2}}{d r_{A}}$. Cramer's rule gives us

$$
\frac{d W_{2}}{d r_{A}}=\frac{\left|\begin{array}{ccc}
A_{11} & -B_{1} & A_{13} \\
0 & -B_{2} & A_{23} \\
A_{31} & 0 & 0
\end{array}\right|}{|D|}=\frac{A_{31}\left[B_{2} A_{13}-B_{1} A_{23}\right]}{|D|}
$$

It is straightforward to see that $A_{31}>0$ since $u^{\prime}\left[W_{2}-c(e)\right]>0$ and $u^{\prime \prime}\left(W_{1}-c(e)\right)<0$. Note that

$$
\begin{aligned}
& B_{2} A_{13}-B_{1} A_{23}=B_{1} A_{23}-B_{2} A_{13}=u^{\prime}\left[W_{2}-c(e)\right] \mu(1-p) c^{\prime}(e) u^{\prime}\left[W_{1}-c(e)\right]\left[p_{e}+p r_{A}\left(W_{1}-c(e)\right) c^{\prime}(e)\right]- \\
& u^{\prime}\left[W_{1}-c(e)\right] \mu p c^{\prime}(e) u^{\prime}\left[W_{2}-c(e)\right]\left[-p_{e}+(1-p) r_{A}\left(W_{2}-c(e)\right) c^{\prime}(e)\right]
\end{aligned}
$$

After rearranging and canceling terms, it will be obvious that the above expression being positive is equivalent to,

(A51) $r_{A}\left[W_{2}-c(e)\right]-r_{A}\left[W_{1}-c(e)\right]<\frac{p_{e}}{p(1-p) c^{\prime}(e)}$.

Hence, the numerator of (A50) is positive if and only if (A51) holds. Since the denominator is assumed to be positive, (A50) is positive so that $W_{2}$ is increasing in the agent's coefficient of absolute risk aversion.

To prove (b), according to Cramer's rule 
(A52) $\frac{d W_{1}}{d r_{A}}=\frac{\left|\begin{array}{ccc}-B_{1} & 0 & A_{13} \\ -B_{2} & A_{22} & A_{23} \\ 0 & A_{32} & 0\end{array}\right|}{|D|}=\frac{B_{1} A_{23} A_{32}-B_{2} A_{13} A_{32}}{|D|}=\frac{A_{32}\left[B_{1} A_{23}-B_{2} A_{13}\right]}{|D|}$.

Since the denominator is positive, (A52) will only be negative if $A_{32}$ and $B_{1} A_{23}-B_{2} A_{13}$ have opposite signs. Note that (A53)

$$
\begin{aligned}
& B_{1} A_{23}-B_{2} A_{13}=u^{\prime}\left[W_{1}-c(e)\right] \mu p c^{\prime}(e) u^{\prime}\left[W_{2}-c(e)\right]\left[-p_{e}+(1-p) r_{A}\left(W_{2}-c(e)\right) c^{\prime}(e)\right]- \\
& u^{\prime}\left[W_{2}-c(e)\right] \mu(1-p) c^{\prime}(e) u^{\prime}\left[W_{1}-c(e)\right]\left[p_{e}+p r_{A}\left(W_{1}-c(e)\right) c^{\prime}(e)\right] .
\end{aligned}
$$

This expression is negative if and only if (after canceling terms and rearranging) (A51) holds. Moreover, one can see from (A46) that $A_{32}$ is positive if and only if (A54) $r_{A}\left(W_{2}-c(e)\right)>\frac{p_{e}}{(1-p) c^{\prime}(e)}$.

Therefore, (A52) is negative if and only if both (A51) and (A54) hold. Alternatively, (A52) can be negative if and only if the inequalities in (A51) and (A54) are both reversed so that $A_{32}$ is negative and $B_{1} A_{23}-B_{2} A_{13}$ is positive. 


\section{FOR ONLINE PUBLICATION}

\section{Appendix B: Instructions for the Endogenous Treatment}

Note: These instructions are for Endogenous treatment. Other instructions can be provided from the authors upon request.

\section{GENERAL INSTRUCTIONS}

This is an experiment in the economics of strategic decision making. Various research agencies have provided funds for this research. The instructions are simple. If you follow them closely and make appropriate decisions, you can earn an appreciable amount of money.

The experiment will proceed in three parts. Each part contains decision problems that require you to make a series of economic choices which determine your total earnings. The currency used in Part 1 and 2 of the experiment is U.S. Dollars. The currency used in Part 3 of the experiment is francs. Francs will be converted to U.S. Dollars at a rate of $\mathbf{1 0}$ francs to $\underline{\mathbf{1}}$ dollar. You have already received a $\mathbf{\$ 2 0 . 0 0}$ participation fee (this includes your show-up fee of \$7.00). Your earnings from Parts 1, 2 and 3 of the experiment will be incorporated into your participation fee. At the end of today's experiment, you will be paid in private and in cash. 18 participants are in today's experiment.

It is very important that you remain silent and do not look at other people's work. If you have any questions, or need assistance of any kind, please raise your hand and an experimenter will come to you. If you talk, laugh, exclaim out loud, etc., you will be asked to leave and you will not be paid. We expect and appreciate your cooperation.

At this time we proceed to Part 1 of the experiment.

\section{INSTRUCTIONS FOR PART 1}

\section{YOUR DECISION}

In this part of the experiment you will be asked to make a series of choices in decision problems. How much you receive will depend partly on chance and partly on the choices you make. The decision problems are not designed to test you. What we want to know is what choices you would make in them. The only right answer is what you really would choose.

For each line in the table in the next page, please state whether you prefer option A or option B. Notice that there are a total of $\mathbf{1 5}$ lines in the table but just one line will be randomly selected for payment. Each line is equally likely to be chosen, so you should pay equal attention to the choice you make in every line. After you have completed all your choices a token will be randomly drawn out of a bingo cage containing tokens numbered from 1 to 15. The token number determines which line is going to be paid.

Your earnings for the selected line depend on which option you chose: If you chose option A in that line, you will receive $\mathbf{\$ 1}$. If you chose option B in that line, you will receive either $\mathbf{\$ 3}$ or $\mathbf{\$ 0}$. To determine your earnings in the case you chose option B there will be second random draw. A token will be randomly drawn out of the bingo cage 
now containing twenty tokens numbered from 1 to 20. The token number is then compared with the numbers in the line selected (see the table). If the token number shows up in the left column you earn $\$ 3$. If the token number shows up in the right column you earn $\$ 0$.

Are there any questions?

\section{Personal Record Sheet for Part 1}

\begin{tabular}{|c|c|c|c|c|}
\hline $\begin{array}{l}\text { Decis } \\
\text { ion } \\
\text { no. }\end{array}$ & $\begin{array}{c}\text { Option } \\
\text { A }\end{array}$ & & $\begin{array}{c}\text { Option } \\
\text { B }\end{array}$ & $\begin{array}{l}\text { Please } \\
\text { choose } \\
\text { A or B }\end{array}$ \\
\hline 1 & $\$ 1$ & \$3 never & $\begin{array}{l}\text { \$0 if } 1,2,3,4,5,6,7,8,9,10,11,12,13,14,15 \text {, } \\
16,17,18,19,20\end{array}$ & \\
\hline 2 & $\$ 1$ & $\$ 3$ if 1 comes out of the bingo cage & $\begin{array}{l}\text { \$0 if } 2,3,4,5,6,7,8,9,10,11,12,13,14,15 \text {, } \\
16,17,18,19,20\end{array}$ & \\
\hline 3 & $\$ 1$ & $\$ 3$ if 1 or 2 comes out & $\begin{array}{l}\text { \$0 } \\
\text { if } 3,4,5,6,7,8,9,10,11,12,13,14,15, \\
16,17,18,19,20\end{array}$ & \\
\hline 4 & $\$ 1$ & $\$ 3$ if 1,2 or 3 & $\begin{array}{l}\text { \$0 if } 4,5,6,7,8,9,10,11,12,13,14,15 \text {, } \\
16,17,18,19,20\end{array}$ & \\
\hline 5 & $\$ 1$ & $\$ 3$ if $1,2,3,4$ & $\begin{array}{l}\text { \$0 if } 5,6,7,8,9,10,11,12,13,14,15 \text {, } \\
16,17,18,19,20\end{array}$ & \\
\hline 6 & $\$ 1$ & $\$ 3$ if $1,2,3,4,5$ & $\begin{array}{l}\text { \$0 if } 6,7,8,9,10,11,12,13,14,15 \\
16,17,18,19,20\end{array}$ & \\
\hline 7 & $\$ 1$ & $\$ 3$ if $1,2,3,4,5,6$ & $\mathbf{\$ 0}$ if $7,8,9,10,11,12,13,14,15,16,17,18,19,20$ & \\
\hline 8 & $\$ 1$ & $\$ 3$ if $1,2,3,4,5,6,7$ & $\mathbf{\$ 0}$ if $8,9,10,11,12,13,14,15,16,17,18,19,20$ & \\
\hline 9 & $\$ 1$ & $\$ 3$ if $1,2,3,4,5,6,7,8$ & $\mathbf{\$ 0}$ if $9,10,11,12,13,14,15,16,17,18,19,20$ & \\
\hline 10 & $\$ 1$ & $\$ 3$ if $1,2,3,4,5,6,7,8,9$ & $\mathbf{\$ 0}$ if $10,11,12,13,14,15,16,17,18,19,20$ & \\
\hline 11 & $\$ 1$ & $\$ 3$ if $1,2,3,4,5,6,7,8,9,10$ & $\mathbf{\$ 0}$ if $11,12,13,14,15,16,17,18,19,20$ & \\
\hline
\end{tabular}




\begin{tabular}{|l||l||l|l||}
\hline 12 & $\mathbf{\$ 1}$ & $\mathbf{\$ 3}$ if $1,2,3,4,5,6,7,8,9,10,11$ & $\mathbf{\$ 0}$ if $12,13,14,15,16,17,18,19,20$ \\
\hline \multirow{2}{*}{13} & $\mathbf{\$ 1}$ & $\mathbf{\$ 3}$ if $1,2,3,4,5,6,7,8,9,10,11,12$ & $\mathbf{\$ 0}$ if $13,14,15,16,17,18,19,20$ \\
\hline \multirow{2}{*}{14} & $\mathbf{\$ 1}$ & $\mathbf{\$ 3}$ if $1,2,3,4,5,6,7,8,9,10,11,12,13$ & $\mathbf{\$ 0}$ if $14,15,16,17,18,19,20$ \\
\hline 15 & $\mathbf{\$ 1}$ & $\mathbf{\$ 3}$ if $1,2,3,4,5,6,7,8,9,10,11,12,13,14$ & $\mathbf{\$ 0}$ if $15,16,17,18,19,20$ \\
\hline
\end{tabular}




\section{INSTRUCTIONS FOR PART 2 YOUR DECISION}

In this part of the experiment you will be asked to make a series of choices in decision problems. For each line in the table in the next page, please state whether you prefer option A or option B. Notice that there are a total of $\mathbf{4}$ lines in the table but just one line will be randomly selected for payment. Each line is equally likely to be chosen, so you should pay equal attention to the choice you make in every line. After you have completed all your choices a token will be randomly drawn out of a bingo cage containing tokens numbered from 1 to 4 . The token number determines which line is going to be paid.

Your earnings for the selected line depend on which option you chose: if you chose option A in that line, you will receive $\mathbf{\$ 2}$ and the other participant who will be matched with you will also receive $\mathbf{\$ 2}$. If you chose option B in that line, you and the other participant will receive earnings as indicated in the table for that specific line. For example, if you chose B in line 2 and this line is selected for payment, you will receive $\mathbf{\$ 3}$ and the other participant will receive $\mathbf{\$ 1}$. Similarly, if you chose B in line 3 and this line is selected for payment, you will receive $\mathbf{\$ 2}$ and the other participant will receive $\mathbf{\$ 4}$. Note that the other participant will never be informed of your personal identity and you will not be informed of the other participant's personal identity.

After you have completed all your choices we will use a bingo cage to determine which line is going to be paid. Then the computer will randomly and anonymously match you with another participant in the experiment. While matching you with another participant, the computer will also randomly determine whose decision to implement. If the computer chooses your decision to implement, then the earnings to you and the other participant will be determined according to your choice of A or B. If the computer chooses the other participant decision to implement, then the earnings will determined according to the other participant choice of A or B.

Are there any questions?

Personal Record Sheet for Part 2

\begin{tabular}{|l||c||c||c|}
\hline $\begin{array}{l}\text { Decis } \\
\text { ion } \\
\text { no. }\end{array}$ & $\begin{array}{c}\text { Distribution A } \\
\text { (you, the other participant) }\end{array}$ & $\begin{array}{c}\text { Distribution B } \\
\text { (you, the other participant) }\end{array}$ & $\begin{array}{c}\text { Please } \\
\text { choose } \\
\text { A or B }\end{array}$ \\
\hline 1 & $\$ 2, \$ 2$ & $\$ 2, \$ 1$ & \\
\hline 2 & $\$ 2, \$ 2$ & $\$ 3, \$ 1$ & \\
\hline 3 & $\$ 2, \$ 2$ & $\$ 2, \$ 4$ \\
\hline
\end{tabular}




\begin{tabular}{|l||l||c||}
\hline 4 & $\$ 2, \$ 2$ & $\$ 3, \$ 5$ \\
\hline
\end{tabular}




\section{INSTRUCTIONS FOR PART 3}

The third part of the experiment consists of 20 decision-making periods. Each period, you will be randomly and anonymously placed into a group which consists of three participants: participant 1, participant 2 and participant 3. At the beginning of the first period you will be randomly assigned either as participant 1, participant 2 or participant 3. You will remain in the same role assignment throughout the entire experiment. So, if you are assigned as participant 2 then you will stay as participant 2 throughout the entire experiment. Each consecutive period you will be randomly regrouped with two other participants of opposite assignment. So, if you are participant 2, each period you will be randomly re-grouped with another participant 1 and another participant 3.

\section{DECISION OF PARTICIPANT 1}

Each period will proceed in two stages. In the first stage, participant 1 will choose a big reward and a small reward for participants 2 and 3: any integer number of francs between 0 and 110. An example of a decision screen for participant 1 is shown below.

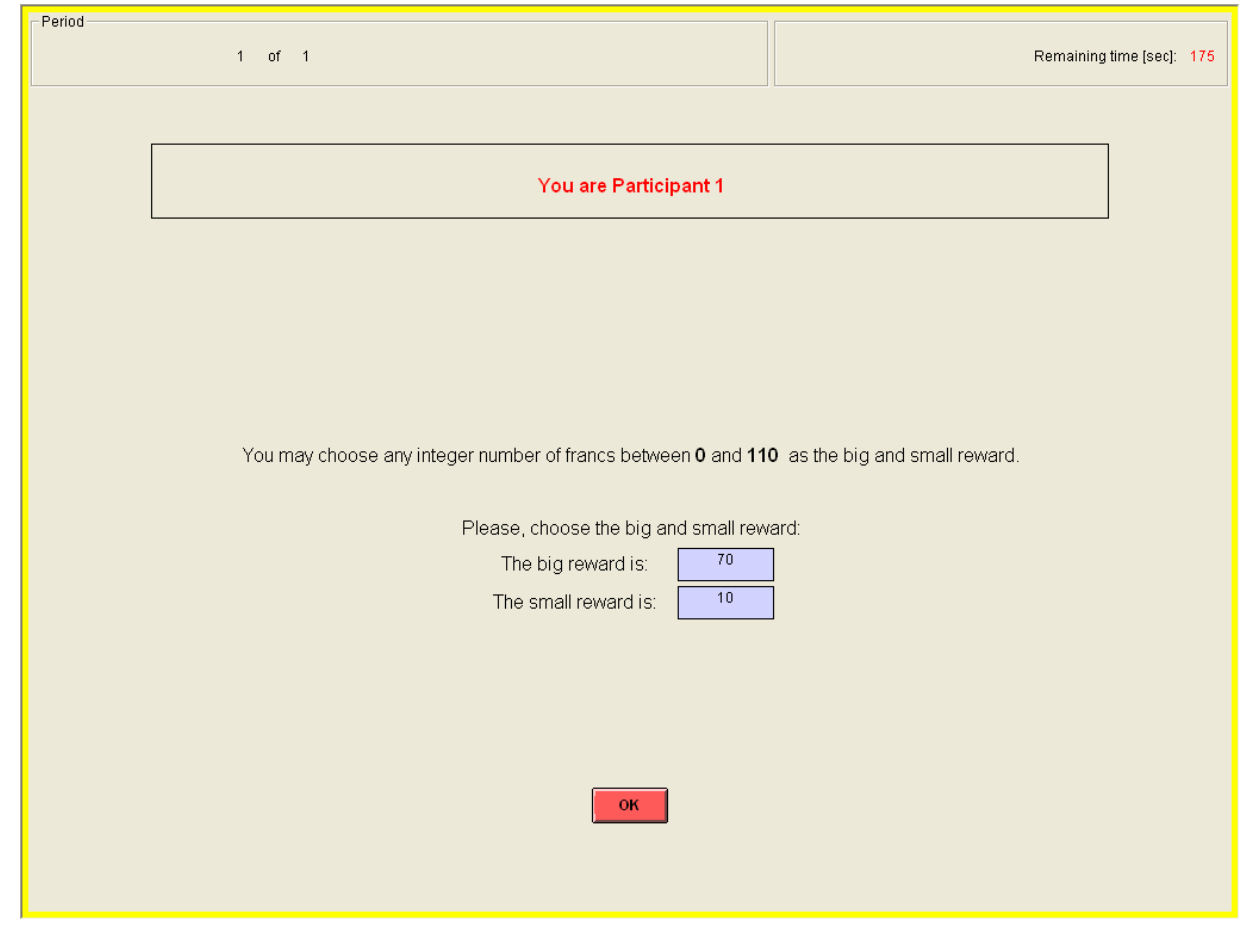

\section{DECISIONS OF PARTICIPANTS 2 AND 3}

The computer will display to participants 2 and 3 the big and small reward chosen by participant 1 . Then in the second stage, participants 2 and 3 will decide whether to choose option A or option B. Participants choosing option B will also have to choose effort level: any integer number between $\mathbf{0}$ and 120. An example of a decision screen for participants 2 and 3 is shown below. 


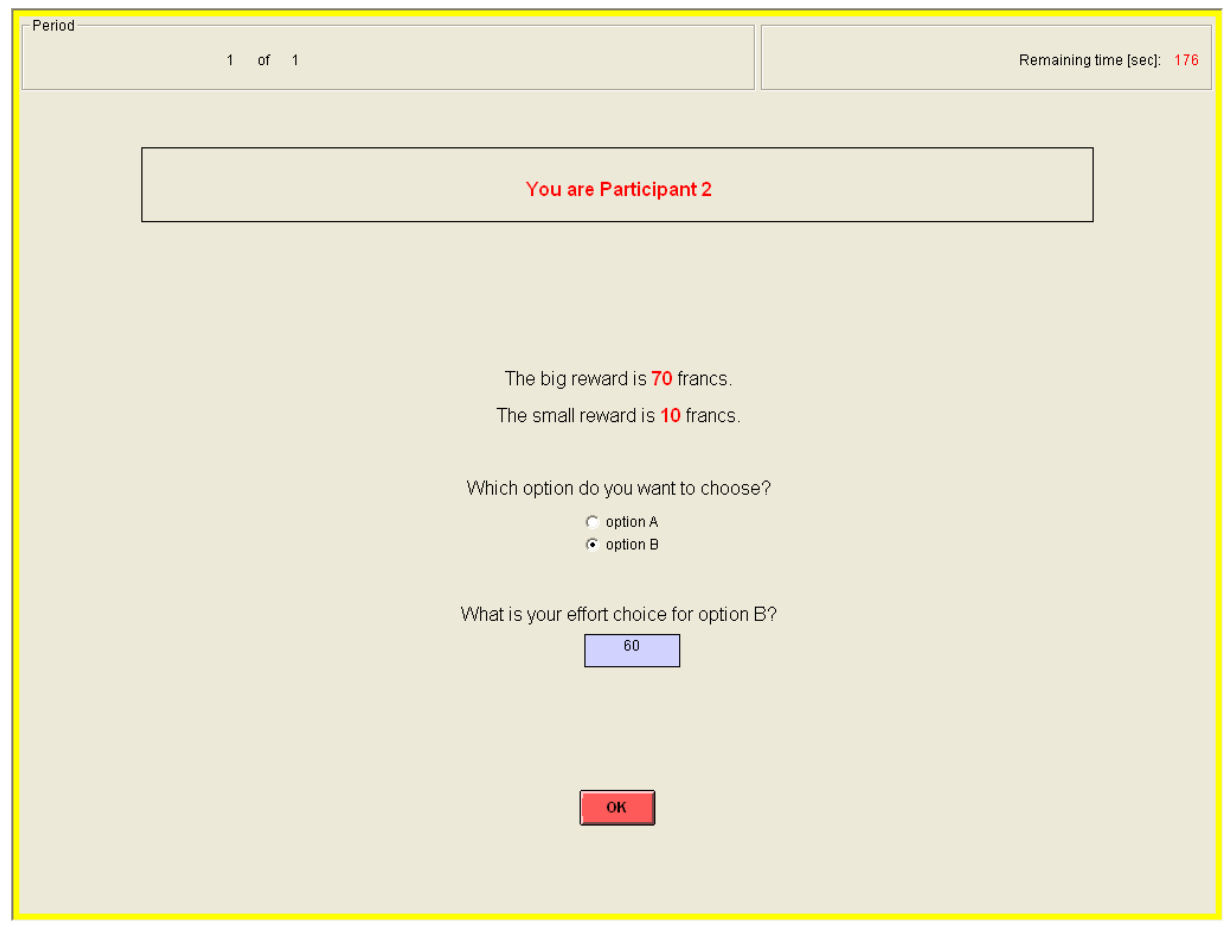

\section{EARNINGS OF PARTICIPANTS 1, 2, AND 3}

\section{Option A}

If at least one participant ( 2 or 3 ) chooses option $A$, then the earnings of all three participants are:

participant1's earnings $=0$

participant 2's earnings $=15$

participant 3's earnings $=15$

\section{Option B}

If both participants 2 and 3 choose option $B$ and respective efforts, then the earnings of participants 1,2 and 3 depend on the big and small reward chosen by participant 1 , the efforts chosen by participants 2 and 3 , and the personal random numbers chosen by the computer.

In particular, for each effort level chosen by participants 2 and 3 there is an associated cost of effort. The cost of effort can be found in the Cost of Effort table attached to these instructions: each possible effort level is given in column A, and its cost is given in column $\mathrm{B}$. Note that as effort rises from 0 to 120 , costs rise exponentially. The cost of effort can be also calculated using the following formula:

$$
\text { cost of effort }=\frac{(\text { effort })^{2}}{120}
$$

After participants 2 and 3 choose their efforts, the computer will add a personal random number to determine participant 2's and 3's performance. This number can take any value between $\mathbf{- 4 0}$ and $\mathbf{+ 4 0}$. Each number between -40 and +40 is equally likely 
to be drawn and there is one separate and independent random draw between -40 and +40 for participant 2 and for participant 3 .

participant 2's performance $=$ [participant 2's effort $]+$ [participant 2's random number $]$ participant 3's performance = [participant 3's effort $]+$ [participant 3's random number]

If participant 2's performance is higher than participant 3's performance, then participant 2 will receive the big reward and participant 3 will receive the small reward. If participant 2's performance is lower than participant 3's performance, then participant 2 will receive the small reward and participant 3 will receive the big reward. In case of a tie, the computer will randomly allocate the big and small reward to participants 2 and 3. Both participants will also have to incur the cost of their efforts regardless of the reward level they receive. Therefore, the earnings of participants 2 and 3 are:

If participant 2 receives the big reward:

participant 2's earnings $=$ [big reward $]-[$ cost of participant 2's effort $]$

participant 3's earnings $=[$ small reward $]-[\operatorname{cost}$ of participant 3 's effort $]$

If participant 3 receives the big reward:

participant 2's earnings $=$ [small reward $]-[\operatorname{cost}$ of participant 2's effort $]$

participant 3's earnings $=$ [big reward $]-$ [cost of participant 3's effort $]$

Note that higher [participant 2's effort] implies higher chance of receiving the [big reward] by participant 2 and higher [cost of participant 2's effort]. Similarly, higher [participant 3's effort] implies higher chance of receiving the [big reward] by participant 3 and higher [cost of participant 3's effort].

Disregarding who receives the big and small reward, the earnings of participant 1 are calculated in the following way:

$$
\begin{aligned}
\text { participant 1's earnings }= & \text { [participant 2's performance }]+[\text { participant 3's performance }] \\
& -[\text { big reward }]-[\text { small reward }]= \\
= & \text { [participant } 2 \text { 's effort }]+[\text { participant } 2 \text { 's random number }]+ \\
& +[\text { participant 3's effort }]+[\text { participant 3's random number }] \\
& -[\text { big reward }]-[\text { small reward }]
\end{aligned}
$$

Note that the earnings of participant 1 depend on the big and small reward chosen by participant 1 , the efforts chosen by participants 2 and 3 , and the random numbers chosen for participants 2 and 3 by the computer. Also note that, the higher is the [participant 2's effort] and [participant 3's effort], the higher is the participant 1's earnings. And on the other hand, the higher is the [big reward] and [small reward], the lower is the participant 1's earnings.

\section{An Example}

Let's say, in the first stage, participant 1 chooses [big reward] as 70 francs and [small reward] as 20 francs. Also, let's say, in the second stage, both participants 2 and 3 choose option B, with [participant 2's effort] $=56$ and [participant 3's effort] $=65$. Then the computer randomly selects +19 and -18 as [participant 2's random number] and [participant 3's random number]. Therefore, since [participant 2's performance] $=56+$ $19=75$ is greater than [participant 3's performance] $=65-18=47$, participant 2 
receives the [big reward] of 70 francs and participant 3 receives the [small reward] of 20 francs.

Therefore, participant 2's earnings $=70-26.13=43.87$, since the [big reward] is 70 francs and the cost of participant 2's effort of 56 is 23.13 francs, as shown in the Cost of Effort table. Similarly, participant 3's earnings $=20-35.21=-15.21$, since the [small reward] is 20 and the cost of participant 3's effort of 65 is 35.21. Finally, participant 1's earnings $=56+19+65-18-70-20=32$, since participant 2's and 3's efforts are 56 and 65 , the random numbers are +19 and -18 , and the big and small rewards are 70 and 20.

\section{END OF THE PERIOD}

At the end of each period, the computer will display the following information on the outcome screen: participant 1's choice of the big and small reward, participant 2's and 3's effort choices, participant 2's and 3's random numbers, participant 2's and 3's performances, the participants who received the big and small reward, and earnings for the period. Once the outcome screen is displayed you should record your results for the period on your Personal Record Sheet under the appropriate heading. This allows you to keep track of performance across periods and to learn from your past experience.

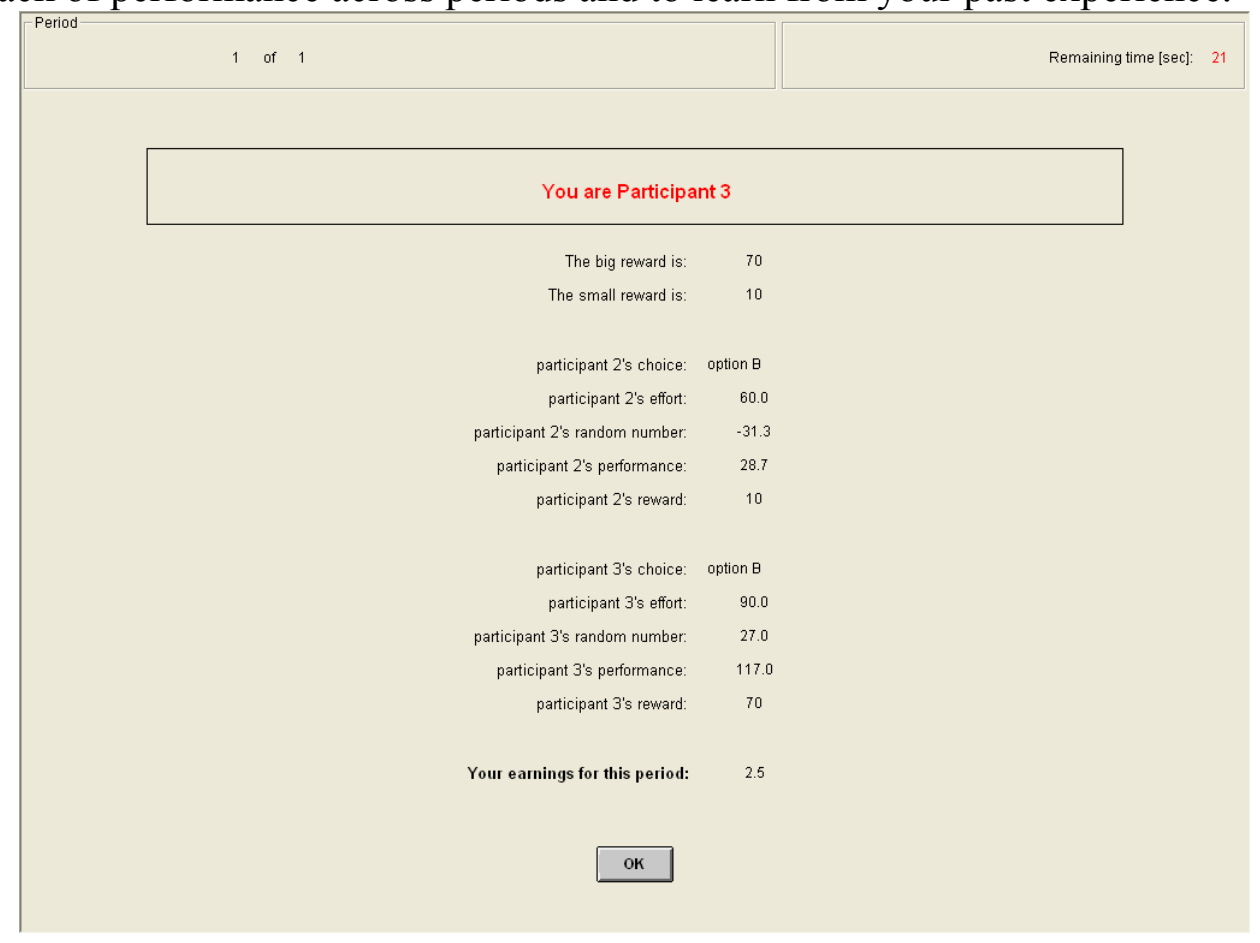

\section{IMPORTANT NOTES}

Each period, you will be randomly and anonymously placed into a group which consists of three participants: participant 1, participant 2 and participant 3 . At the beginning of the first period you will be randomly assigned either as participant 1, participant 2 or participant 3 . You will remain in the same role assignment throughout the entire experiment. So, if you are assigned as participant 2 then you will stay as 
participant 2 throughout the entire experiment. Each consecutive period you will be randomly re-grouped with two other participants of opposite assignment. So, if you are participant 2 , each period you will be randomly re-grouped with another participant 1 and another participant 3. No participant will be informed of any other participants personal identity.

In the first stage, participant 1 will chose a big reward and a small reward for participants 2 and 3. The computer will display to participants 2 and 3 the big and small rewards chosen by participant 1 . Then in the second stage, participants 2 and 3 will decide whether to choose option A or option B. Participants choosing option B will also have to choose effort level. If at least one participant ( 2 or 3 ) chooses option A, then the computer will assign earnings of 0,15 , and 15 to participants 1,2 , and 3 . If both participants 2 and 3 choose option B and respective efforts, then based on these efforts, the computer will assign the big reward either to participant 2 or participant 3 . Finally, the computer will calculate the earnings of participant 1,2 , and 3 based on the decisions they made and will display all relevant information for the period on the outcome screen.

Remember you have already received a $\mathbf{\$ 2 0 . 0 0}$ participation fee. In this part of the experiment, depending on a period, you may receive either positive or negative earnings. At the end of the experiment we will randomly select $\mathbf{4}$ out of 20 periods for actual payment using a bingo cage. You will sum the total earnings for these 4 periods and convert them to a U.S. dollar payment. If the earnings are negative, we will subtract them from your earnings. If the earnings are positive, we will add them to your earnings.

Are there any questions? 


\section{QUIZ}

1. Suppose that you are assigned to be in the role of participant 1 in period 1 . Will your role in period 2 change?

Answer: Yes / No

2. Suppose that you are assigned to be in the role of participant 2. Will you always be matched with the same participants 1 and 3 or will you be randomly re-paired with different participants in role 1 and 3 each period?

Answer: Yes / No

3. Suppose that you are assigned to be participant 3. Suppose that in a particular period, participant 1 chose a big reward of 75 francs and a small reward of 20 francs. Suppose that you choose Option B and participant 2 also chooses Option B. Then suppose that you choose an effort of 40 and the computer chooses a personal random number for you of +30 . Finally, suppose that participant 2 's effort is 45 and his random number is +10 . How many francs did you earn in this period?

Answer:

4. Suppose that you are assigned to be participant 2. Suppose that in a particular period, participant 1 chose a big reward of 75 francs and a small reward of 20 francs. Suppose that you choose Option B and participant 3 also chooses Option B. Then suppose that you choose an effort of 35 and the computer chooses a personal random number for you of +20 . Finally, suppose that participant 3 's effort is 80 and random number is -20 . How many francs did you earn in this period?

Answer:

5. Suppose that you are assigned to be participant 1. Suppose that in a particular period, you chose a big reward of 75 francs and a small reward of 20 francs. Suppose that both participants 2 and 3 choose Option B. Participant 3's performance ends up being 70 and participant 2's performance ends up being 55. How many francs did you earn in this period?

Answer: 


\begin{abstract}
ANSWER
1. Correct Answer: No. You will remain in the same role across all periods. Therefore, you will still remain in the role of participant 1 in period 2.

2. Correct Answer: No. If you are participant 2 you will be randomly re-paired with another participant 1 and participant 3 each period.

3. Correct Answer: 61.67. Your earning is [big reward] - [cost of effort] which is 75$13.33=61.67$ francs. Note you received the big reward because your performance of 70 (effort of $40+$ random number of 30) exceeds participant 2's performance of 55 (effort of $45+$ random number of 10$)$.

4. Correct Answer: 9.79. Your earnings is [small reward] - [cost of effort] which is 20$10.21=9.79$ francs. Note that you received the small reward because your performance of 55 (effort of $35+$ random number of 20) is smaller than participant 3 's performance of 60 (effort of 80 - random number of 20).

5. Correct Answer: 30. Recall that your earnings is [participant 2's performance] + [participant 1's performance] - [big reward] - [small reward] $=55+70-75-20=30$. Therefore, you earned 30 francs in this period.
\end{abstract}

